\title{
Cardiovascular diseases related to ionizing radiation: The risk of low-dose exposure (Review)
}

\author{
BJORN BASELET ${ }^{1,2 *}$, CHARLOTTE ROMBOUTS $^{1,3^{*}}$, ABDERRAFI MOHAMMED BENOTMANE $^{1}$, \\ SARAH BAATOUT ${ }^{1,3}$ and AN AERTS ${ }^{1}$ \\ ${ }^{1}$ Radiobiology Unit, Institute for Environment, Health and Safety, Belgian Nuclear Research Centre (SCK・CEN), Mol; \\ ${ }^{2}$ Pole of Pharmacology and Therapeutics, Institute of Experimental and Clinical Research, University of Louvain \\ Medical School, Brussels; ${ }^{3}$ Department of Molecular Biotechnology, Ghent University, Ghent, Belgium
}

Received June 1, 2016; Accepted September 7, 2016

DOI: $10.3892 /$ ijmm.2016.2777

\begin{abstract}
Traditionally, non-cancer diseases are not considered as health risks following exposure to low doses of ionizing radiation. Indeed, non-cancer diseases are classified as deterministic tissue reactions, which are characterized by a threshold dose. It is judged that below an absorbed dose of $100 \mathrm{mGy}$, no clinically relevant tissue damage occurs, forming the basis for the current radiation protection system concerning non-cancer effects. Recent epidemiological findings point, however, to an excess risk of non-cancer diseases following exposure to lower doses of ionizing radiation than was previously thought. The evidence is the most sound for cardiovascular disease (CVD) and cataract. Due to limited statistical power, the dose-risk relationship is undetermined below $0.5 \mathrm{~Gy}$; however, if this relationship proves to be without a threshold, it may have considerable impact on current low-dose health risk estimates. In this review, we describe the CVD risk related to low doses of ionizing radiation, the clinical manifestation and the pathology of radiation-induced CVD, as well as the importance of the endothelium models in CVD research as a way forward to complement the epidemiological data with the underlying biological and molecular mechanisms.
\end{abstract}

\section{Contents}

1. Cardiovascular disease risk related to low doses of ionizing radiation

2. Clinical manifestation and pathology of radiation-induced cardiovascular diseases

Correspondence to: Professor Sarah Baatout, Radiobiology Unit, Institute for Environment, Health and Safety, Belgian Nuclear Research Centre (SCK $\cdot$ CEN), Mol, Boeretang 200, 2400 Mol, Belgium

E-mail: sbaatout@sckcen.be

${ }^{*}$ Contributed equally

Key words: cardiovascular disease, ionizing radiation, low dose research, endothelial cells, radiobiology
3. Molecular and cellular mechanisms underlying the observed radiation-induced cardiovascular disorders

4. Conclusion

\section{Cardiovascular disease risk related to low doses of ionizing} radiation

Recognition of radiation-related cardiovascular disease (CVD) risk. The recognition that exposure of the heart and the vasculature to high doses of ionizing radiation can cause CVD began in the late 1960s (1). This was mainly related to the clinical observation of cardiovascular complications in radiation-treated survivors of Hodgkin's lymphoma and other childhood cancers. Later, larger-scale epidemiological studies found a clear association between therapeutic doses of thoracic irradiation and an increased risk of CVD in these long-term cancer survivors, confirming the earlier observations (2).

An excess risk of CVD was also observed after postoperative radiotherapy for breast cancer. In these patients, a part of the heart received accumulated doses of $\geq 40$ Gy (fractionated 20x2 Gy). After correction for fractionation effects using the linear quadratic model and an $\alpha / \beta$ ratio of $1-3$ Gy, determined in experimental studies in the rat heart, Schultz-Hector and Trott calculated that this corresponds to equivalent single doses to the total heart of approximately 1-2 Gy (3). The Early Breast Cancer Trialists' Collaborative Group performed a metaanalysis on mortality data of $>30.000$ breast cancer patients 15 years after treatment. The mortality of heart disease was increased by $27 \%$ in patients treated with surgery and subsequent radiotherapy compared to patients treated with surgery alone (4). The evaluation of long-term mortality in breast cancer survivors may however be influenced by the varying prognosis of the different treatment regimens (surgery vs. radiotherapy). This can be circumvented by comparing women irradiated for left-sided tumours with women irradiated for right-sided tumours. Cardiac radiation doses are larger in radiotherapy patients with left-sided tumours than in radiotherapy patients with right-sided tumours (5). An analysis of 308,861 women with breast cancer registered in the Surveillance, Epidemiology and End-Results cancer registries database from the United States revealed an increased heart disease mortality ratio for 
women irradiated for left-sided breast cancer compared to those irradiated for right-sided breast cancer (6). A study related to 72,134 women diagnosed with breast cancer in Denmark and Sweden during the years 1976-2006 and a follow-up of 30 years revealed an increased risk of ischemic heart disease (IHD), pericarditis and valvular disease in irradiated women with leftsided tumours (mean cardiac dose $6.3 \mathrm{~Gy}$ ) compared to those with right-sided tumours (mean cardiac dose 2.7 Gy) (7).

In addition, patients with benign diseases, such as peptic ulcers treated with radiotherapy form interesting study cohorts. For instance, coronary heart disease-related mortality was compared between peptic ulcer patients treated with radiotherapy $(n=1859)$ and those treated by other means $(n=1860)(8)$. The calculated received volume-weighted cardiac doses ranged from 1.6 to $3.9 \mathrm{~Gy}$ and the portion of the heart directly in the radiation field received doses of 7.6-18.4 Gy. A significantly increased risk of coronary heart disease-related mortality was observed with the increasing dose. Only recently, various epidemiological findings, in particular from the Japanese atomic bomb survivors, have raised awareness of possible CVD risk following exposure to low and moderate doses of radiation (3). Below an overview is given of the major epidemiological findings related to CVD risk following low-dose exposure.

\section{Low-dose exposed epidemiological cohorts}

Classification of CVD in epidemiology. Reviewing the epidemiological literature related to CVD and low-dose ionizing radiation is complicated by the different classifications of CVD. Moreover, all types of CVD are often pooled in one diagnosis in epidemiological studies. This hampers the thorough understanding of radiation-related CVD risk, and distinction should be made between the different clinical manifestations. In addition, many epidemiological studies face the problem of misclassification of the cause of death, except for stroke, for which the diagnosis tends to be reasonably good (9). In fact, stroke is not considered to be a CVD, but a circulatory disease since it involves the blood circulation in the brain and is unrelated to the heart. It is defined by brain injury, which occurs when a blood vessel in the brain ruptures, leading to haemorrhage, or when a blood vessel is blocked, leading to ischemia following the loss of blood supply in the brain area of concern.

Patients treated with radiation therapy $(R T)$. External beam RT for breast cancer, Hodgkin's lymphoma, or even peptic ulcer disease in the early days often involves some incidental exposure of the heart. There are studies pointing to late secondary cardiovascular effects due to this scattered radiation exposure. Long-term follow-up was shown to be essential, as the cardiovascular complications may manifest years after the completion of RT.

Most peptic ulcers are caused by an infection with a type of bacteria known as Helicobacter pylori and are nowadays treated, at least partly, with antibiotics. However, mid-last century peptic ulcer disease patients were irradiated. Peptic ulcer disease patients treated with RT $(n=1859)$ or by other means $(n=1860)$ at the University of Chicago Medical Center between 1936 and 1965, were followed through 1997 by Carr et al (8). The irradiated patients received volume-weighted cardiac doses ranging from 1.6 to $3.9 \mathrm{~Gy}$ and the portion of the heart directly in the radiation field received doses of 7.6-18.4 Gy. The observed numbers of cause-specific deaths were compared with the expected numbers from the general population rates. Greater than expected coronary heart diseaserelated mortality was observed among the irradiated patients. The excess coronary heart disease risk in patients who received RT for peptic ulcer disease decades before indicates the need for long-term follow-up of CVD after chest RT.

Over the last half century, RT has evolved to become one of the cornerstones of treatment for various types of cancer. It is estimated that $>50 \%$ of patients with cancer are treated with radiotherapy. Along with the development of novel chemotherapeutic agents, RT has revolutionized the prognosis of patients with various types of cancer. Cancers during childhood and adolescence are now more and more successfully treated and these patients go on to live an active and normal adult life, as evident by an increasing number of cancer survivors. Late cardiovascular effects are often observed in cancer survivors (10). Hodgkin's lymphoma was the earliest paradigm for the study of radiation-induced vascular disease. A first case report was published in 1924 about histological changes in the human heart after irradiation for Hodgkin's lymphoma (11). Amongst Hodgkin's lymphoma patients who received radiation, CVD is of the most common causes of death. Studies have shown that these patients have an increased risk of coronary artery disease, valvular heart disease, congestive heart failure, pericardial disease and sudden death. The risk is particularly high in patients treated before the age of 40 years (12-15).

In addition, RT for breast cancer often involves some incidental exposure of the heart to ionizing radiation. Darby et al (16) conducted a population-based case-control study of major coronary events (i.e., myocardial infarction, coronary revascularization, or death from IHD) in 2,168 women who underwent radiotherapy for breast cancer between 1958 and 2001 in Sweden and Denmark. The overall average of the mean doses to the whole heart was $4.9 \mathrm{~Gy}$ (range, 0.03-27.72). The rates of major coronary events increased linearly with the mean dose to the heart by $7.4 \%$ /gray [95\% confidence interval (CI), 2.9-14.5; $\mathrm{P}<0.001]$, with no apparent threshold. The increase began within the first 5 years after radiotherapy and continued into the third decade after radiotherapy.

Due to improvements in radiation techniques (e.g., breathingadapted RT, CyberKnife), the risk of cardiovascular complications in relation to radiation are uncertain, but may be expected to decline. However, patients with classical risk factors, such as hypertension, smoking and hyperlipidaemia may be at an increased risk of radiation-related cardiovascular complications, and these risk factors should be treated aggressively (10). Younger patients should be screened, as this patient population at risk usually has a considerable life expectancy.

Survivors of the atomic bombings of Hiroshima and Nagasaki. The most informative cohort is the Life Span Study (LSS), consisting of 120,321 exposed and non-exposed individuals selected from respondents to the national census of Japan in 1950 calling for survivors exposed to the bombings in Hiroshima and Nagasaki, and from residential surveys in the cities after the national census. Mortality in this population has been investigated since the 1950s by collecting information through the national population registry (koseki) and death certificates obtained throughout Japan. Cancer incidence data was available from population-based cancer registries since 1957 in Hiroshima and since 1958 in Nagasaki (17). Next to 

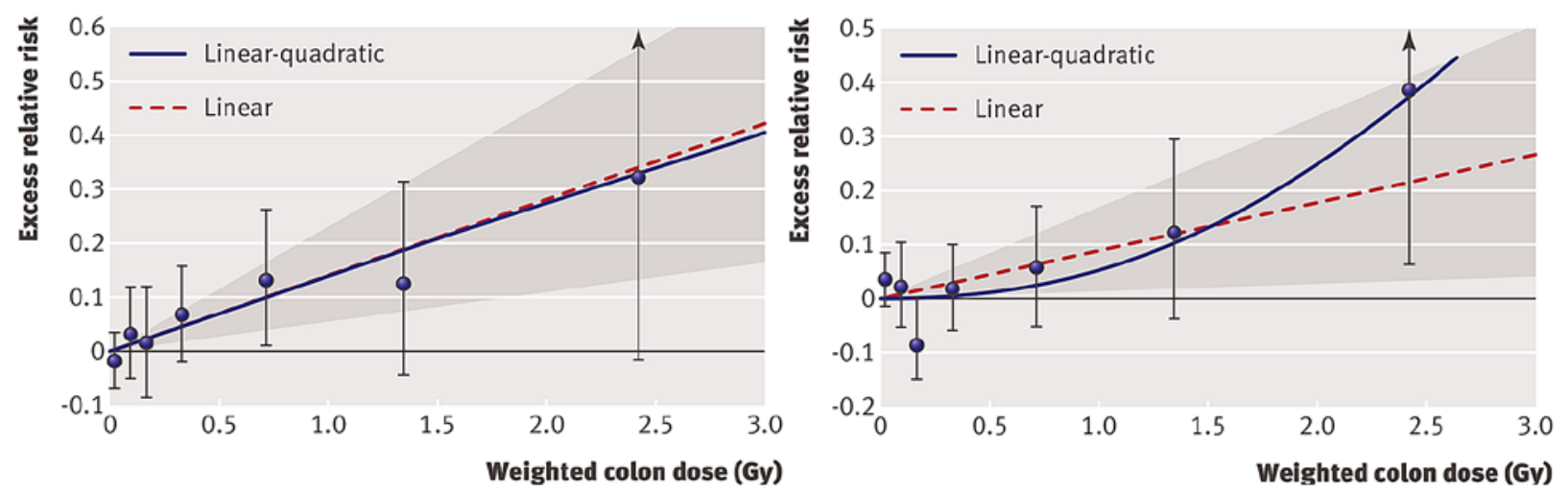

Figure 1. Radiation dose-response relationship (ERR/Gy) in the Life Span Study (LSS) cohort for death from stroke (left panel) and death from heart disease (right panel), showing linear-quadratic and linear functions. Shaded areas represent 95\% confidence region for the fitted linear line. Error bars represent 95\% CI for each dose category risks and the bullet represents the point estimate of risk for each dose category. The participants were divided into several dose categories according to their weighted colon dose (in Gy, $\gamma$ dose plus 10 times neutron dose) (21).

the availability of these data, the large size, the presence of both genders and all ages, and well-characterized individual dose estimates makes this cohort a valuable source for risk estimation. Another cohort, the Adult Health Study (AHS), was established in 1958 and consists of 19,961 subjects from the LSS cohort. These survivors underwent biennial health examinations, which provided additional clinical and subclinical information to the death and cancer registries data. In this way, disease morbidity for a variety of conditions can be investigated (18).

Preston et al evaluated non-cancer mortality based on the LSS report 13 published by the Radiation Effects Research Foundation (RERF), which covers the time period between 1950-1997 (19). In their study, the weighted colon doses from the DS86 dosimetry system were used for individual dose estimates. Only the period between 1968-1997 was included to account for the 'healthy survivor' selection effect. Individuals had to be alive in 1950 to enter the LSS cohort and have thus survived the difficult conditions after the bombing, which means that the health experience of this cohort may not be typical for a normal population. This is reflected as a decrease in noncancer mortality during 1950-1960 in the LSS members that received doses below $2 \mathrm{~Sv}$, as shown by Shimizu et al (20). This 'healthy survivor' selection effect had largely disappeared by the mid-1960s. To exclude this confounding effect, Preston et al advised to restrict the analyses to proximal survivors who were within $3 \mathrm{~km}$ of the hypocenter of the bombing, and to a follow-up period starting from 1968 (19). Based on the linear no-threshold model (LNT) model, excess relative risk (ERR) estimates were calculated to be 0.17 with $90 \%$ CI (0.08-0.26) for heart disease and 0.12 (90\% CI, 0.02-0.22) for stroke, for the period between 1968-1997 (19).

Shimizu et al evaluated ERR of mortality from heart disease and stroke in the LSS cohort with a follow-up of 53 years (19502003) (21). For individual dose estimates, weighted colon doses (Gy) from the DS02 dosimetry system were used. In addition, the authors obtained, by a mail survey, information regarding sociodemographic (education, occupation type), lifestyle (smoking, alcohol intake) and health variables (obesity, diabetes mellitus) from 36,468 members of the LSS cohort. This allowed them to evaluate the effect of these confounding factors on ERR estimates. It should be noted that they included the full follow-up period from 1950-2003 and all survivors, thus not taking into account the 'healthy survivor' selection effect. For the detrimental health outcomes of heart diseases and stroke there is, however, no healthy survivor selection effect. This has recently been confirmed by Schöllnberger et al (23) following the comments of Little et al (22). Shimizu et al (21) found an ERR of 0.14 (95\% CI, 0.06-0.23) for heart disease and an ERR of 0.09 (95\% CI, 0.01-0.17) for stroke based on the LNT model. Whereas the LNT model fitted best the data for heart disease, the quadratic model was best to fit the data for stroke (Fig. 1). The latter model implies relatively little risk at lower doses. Indeed, the calculation of ERR for stroke over restricted dose ranges revealed an ERR of 0.03 (95\% CI, -0.10-0.16) for 0-1 Gy and -0.07 (95\% CI, -0.28-0.16) for 0-0.5 Gy. Furthermore, they showed that the association of dose with CVD risk in the LSS cohort is unlikely to be an artefact from confounding by sociodemographic, lifestyle or disease risk factors.

The above-mentioned studies have used the LSS cohort for CVD risk estimations. Takahashi et al examined the association with dose and the incidence of stroke in the AHS cohort (18). For their study, information of health examinations from the follow-up from 1980 onwards has been used, resulting in 9,515 AHS participants. For individual dose estimates, weighted colon doses (Gy) from the DS02 dosimetry system were used. In this study population, risk for haemorrhagic stroke was observed to increase with dose. This was across the full range of doses for men, while in women there seems to be a threshold of approximately $1.3 \mathrm{~Gy}$.

Occupational exposure. Studies on radiation workers are of interest since they generally involve relatively low doses received over repeated exposures, although in some cases, accumulated doses may be high. Various studies have been performed, of which the most important will be discussed. The largest studied cohort consists of 275,000 nuclear industry workers from 15 countries, referred to as the 15-country study (24). The average cumulative dose received was $20.7 \mathrm{mSv}$. An overall increasing trend, although not significant, for circulatory disease mortality was observed. It was concluded that their findings are compatible with both no increased risk and with an increased risk comparable to that observed in A-bomb survivors. The Chernobyl liquidator cohort consisted of 61,017 individuals with an average cumulative dose of 
0.109 Gy. An ERR/Gy of 0.41 (95\% CI, 0.05-0.78) was found for IHD morbidity and 0.45 (95\% CI, 0.11-0.80) for the morbidity of cerebrovascular diseases, though the outcomes were not adjusted for recognized risk factors such as excessive weight, hypercholesterolemia, smoking, alcohol consumption and others (25). A study by Muirhead et al revealed an increasing circulatory disease mortality risk with dose, which was borderline significant, in the UK National Registry of Radiation Workers in the industrial and medical field (26). The average cumulative dose received was $24.9 \mathrm{mSv}$. This finding should, however, be interpreted with caution due to the lack of information on confounding factors. Another large cohort consisted of 206,620 radiation workers in the industrial and medical field, registered in the National Dose Registry of Canada (27). The average exposure of all workers was $6.3 \mathrm{mSv}$, with large differences between males $(10.6 \mathrm{mSv})$ and females $(1.7 \mathrm{mSv})$. A significant increasing trend of circulatory disease mortality with dose was observed in males. Again, there is a lack of information on confounding factors and there is also incompleteness of dose records. Finally, a recent publication studied a $34 \%$ increase in stroke incidence after a survey during the years 1994-2008 of a cohort of 90,957 radiologic technologists who worked with fluoroscopically guided interventional procedures (28). In addition, mortality from stroke was also modestly elevated, although not statistically significant. No statistically significant excess risks of incidence or mortality were observed from any other cardiovascular disorders evaluated.

The Mayak cohort is of particular interest since it includes information both on mortality and morbidity, and information on confounding factors (29). In 1948, the first nuclear energy enterprise in Russia, Mayak Plutonium Association, became operational. Since 1948 the Mayak personnel undergo regular routine medical examinations. In addition, every 3-5 years a more detailed examination is carried out in a specialized hospital. This examination system led to a unique archive of medical data, which was used to create the 'Clinic' medicaldosimetric database. In addition, from a dosimetric point of view, the database is sound. Individual dosimetry for external gamma exposure was introduced at the beginning of 1948 and for internal exposure during the 1960s (29). Complete data are available for 12,585 Mayak workers employed during the years 1948-1958 and followed-up until December 2000. The mean cumulated external dose was $0.91 \pm 0.95 \mathrm{~Gy}(99 \%$ percentile $3.9 \mathrm{~Gy})$ for men and $0.65 \pm 0.75 \mathrm{~Gy}(99 \%$ percentile $2.99 \mathrm{~Gy})$ for women. In this cohort, a significant increasing trend in IHD morbidity was observed with the increasing total external dose [ERR/Gy=0.11 (95\% CI, 0.049-0.168)]. The influence of confounding factors on this trend was minimal (30). A follow-up study involved the analysis of a cohort including 18,763 Mayak workers with an additional follow-up of 5 years (31). Overall, risk estimates for IHD were similar to the earlier study [ERR/ $\mathrm{Gy}=0.10$ (95\% CI, 0.045-0.153)]. Remarkable though, a statistically significant decrease in IHD incidence was found among workers exposed to external doses of 0.2-0.5 Gy compared to workers exposed to external doses below $0.2 \mathrm{~Gy}$. This decreased risk is heavily influenced by the observations in female workers. The authors further noted that this finding should be interpreted with caution since it has never been reported in other studies. The latter analysis was further updated and extended by looking at the lag-time to progression of IHD and by using the updated dosimetry system MWDS-2008 (32) . In that study, it was observed that the main detrimental effects of external radiation exposure occurred after $>30$ years. In addition, a statistically significant risk was observed in men for mortality caused by IHD [ERR/Gy=0.09 (95\% CI, 0.02-0.16)] while the risk was not significant for women. Recently, Azizova et al published a study regarding incidence and mortality from IHD in an extended cohort of 22,377 Mayak workers first employed during the years 1948-1982 and followed-up to the end of 2008 (33). Risk analysis demonstrated a significant increasing trend in IHD incidence, but not mortality, with total dose from external gamma-rays after having adjusted for non-radiation factors and dose from internal radiation. ERR/Gy for IHD incidence in males was 6-fold higher than in females. In addition, a significant increasing linear trend was observed in IHD mortality, but not incidence, with total absorbed dose from internal alpha radiation to the liver after having adjusted for non-radiation factors and doses from external gamma-rays.

In the same Mayak population, the incidence of and mortality from cerebrovascular disease was studied (34). The cohort consisted of 22,377 workers from the extended Mayak worker cohort that was followed-up to the end of 2008. In this study, the workers were exposed to a mean cumulated external dose of $0.54 \pm 0.76$ Gy $(95 \%$ percentile $2.21 \mathrm{~Gy})$ for men and $0.44 \pm 0.65 \mathrm{~Gy}(95 \%$ percentile $1.87 \mathrm{~Gy})$ for women. After correction for confounding factors, a significant increasing trend in cerebrovascular disease incidence was observed with increasing total external dose $[E R R / G y=0.46$ (95\% CI, 0.37-0.57)]. In addition, the authors showed that the cerebrovascular disease incidence was significantly higher in workers with a total external dose $>0.1$ Gy when compared to those exposed to lower doses. Restricting the analysis to a subcohort with negligible internal exposure for incidence of cerebrovascular disease supports a dose response sub-linear for low doses for incidence of cerebrovascular disease (35). In that study, the excess relative risk/dose was confirmed to be significantly higher for the incidence of cerebrovascular disease in comparison to cerebrovascular disease mortality and the incidence of stroke. The authors hypothesized that this difference was based on the complex nature of cerebrovascular diseases. The incidence was mainly related to chronic forms of cerebrovascular disease, while the mortality was mostly caused by the acute forms. Finally, having a young age during exposure was observed to be an important, aggravating modifier of radiation risk for incidence of cerebrovascular disease and stroke.

It should be noted that apart from the classical vascularrelated confounding factors, occupational studies have to deal with the 'healthy worker' selection effect, similar to the 'healthy survivor' selection effect in A-bomb survivors. The 'healthy worker' selection effect occurs when workers who are healthier and have lower mortality and morbidity rates are selectively retained in the workplace, as such accumulating higher doses. One can adjust for this confounding factor by considering the duration of employment as a confounding factor in the analysis, as done in the 15-country study (24).

Meta-analysis of epidemiological data. The Advisory Group on Ionizing Radiation (AGIR) from the Health Protection Agency reviewed the available epidemiological data for low- and moderate-dose exposure in 2010. Taking all the studies together, they reported a small, but statisti- 
cally significant overall ERR/Gy of 0.09 (95\% CI, 0.07-0.12). AGIR noticed, however, that there was a lot of heterogeneity in risk estimates of the different studies included in their metaanalysis (9). Little et al recently extended this meta-analysis (36). They estimated excess risks for four subgroups of circulatory disease, classified according to the 'International Classification of Diseases, 10th revision': IHD, non-IHD, cerebrovascular disease and all other circulatory diseases. A significant effect of heterogeneity between the different studies was found for cerebrovascular disease and other circulatory diseases, but not for IHD and non-IHD. ERR were calculated based on the LNT model, which implicitly assumes a linear association of CVD risk at low doses and dose rates. They noted that this assumption is reasonable since there is little evidence for non-linearity in the Japanese atomic bomb survivors and Mayak workers data. Furthermore, at least for IHD and non-IHD, the ERR/Sv was consistent between the Japanese atomic bomb survivors, Mayak workers and other occupational cohorts (36). Although it should be noted that Schöllnberger et al and others advocate for the consideration and testing of other dose-response models for non-cancer effects $(32,37)$. To conclude, the overall consensus of the above-mentioned studies is that there is a significant elevated CVD risk for doses $>0.5$ Gy $(9,38)$.

Epidemiology alone is not the answer. CVD is the leading cause of mortality and morbidity and accounts for $30-50 \%$ of all deaths in most developed countries. It is a multifactorial disease with many risk factors, such as lifestyle and other personal factors (39). The most established risk factors include the male gender, elevated low-density lipoprotein (LDL) levels, smoking, hypertension, a family history of premature coronary disease and diabetes mellitus (40). Epidemiological studies, as presented above, have limited statistical power to detect a possible excess risk of CVD following low-dose exposure $(<0.5 \mathrm{~Gy})$, due to the high background level of CVD in the population as a whole and many potentially confounding risk factors (9). For example, it has been calculated that, if the excess risk is in proportion to dose, a cohort of 5 million individuals would be needed to quantify the excess risk of a $10 \mathrm{mSv}$ dose (41). Other factors that have an influence on epidemiological results are the distribution of the dose range, the accuracy of dosimetry, the duration of follow-up after exposure and correct assignment of cause of mortality, as reviewed by Borghini et al (42).

Although epidemiological studies have led to a better insight in radiation-related CVD risk, there are still many uncertainties that need to be clarified. These include whether there is a threshold dose; whether the latency of CVD development is dependent on the dose; the identification of the sensitive targets in the heart and vasculature; whether exposure has an impact on CVD incidence or progression, or both; and the exact impact of acute, fractionated or chronic exposure on risk estimates. For an accurate dose risk assessment, these questions need to be answered.

Classical epidemiological studies, as described above, do not provide all the needed insight to answer these questions. A more targeted approach, such as the integration of epidemiology and biology is required. For example, the assessment of subclinical endpoints and other cardiovascular biomarkers by functional imaging in patients receiving radiotherapy may provide insight into the development and progression of CVD following radiation exposure $(39,42)$. Single-photon emission computed tomography (SPECT) or positron emission tomography (PET) imaging of micro-vascular perfusion has already been applied in breast cancer studies. The outcome differed between studies. For instance, whereas in one study perfusion defects were observed within 6-12 months after radiotherapy (43), no significant differences in perfusion defects were found in another study (44). In addition, the evaluation of cardiovascular biomarkers in patients receiving radiotherapy may be useful. For instance, elevated levels of N-terminal proB-type natriuretic peptide (NT-proBNP) in the blood $(45,46)$ have been shown to be predictive for heart failure and/or CVD mortality across a broad range of individuals (47). Higher values of NT-proBNP were found in patients treated with radiotherapy for left-sided breast cancer compared to patients treated with other means (48).

Next to epidemiology, radiobiological research is essential for understanding CVD risk specifically in the low-dose region. Since epidemiological findings for low and moderate doses are suggestive and not persuasive, their use in dose risk assessment is limited. A thorough understanding of the biological and cellular mechanisms gathered through experimental studies is thus needed to complement the epidemiological findings. Once we have a comprehensive understanding of the underlying biological mechanisms, biologically-based dose-response models can be included in the dose risk assessment. This may prove to be beneficial for an accurate risk estimation in the low-dose region (49).

Societal concern. The possible excess risk of CVD following exposure to low doses is of great societal concern. According to the ICRP, a dose of $0.5 \mathrm{~Sv}$ may lead to approximately $1 \%$ of exposed individuals developing cardiovascular or cerebrovascular disease $>10$ years following exposure, in addition to the $30-50 \%$ suffering from disease without being exposed to ionizing radiation (50). Although the assumed risk is rather small, it may have serious implications for public health. Indeed, seeing the high background rate of CVD, the absolute number of excess cases would be substantial (42).

Various issues, such as occupational radiation exposure, the future of nuclear power, manned space flights and the threat of radiological terrorism, call for a thorough understanding of low-dose health risks (41). The main concern is, however, the increasing use of ionizing radiation for diagnostic medical purposes (Fig. 2) (51). For instance, since 1993, the number of computed tomography (CT) scans has quadrupled in the US and similar trends are observed in Europe (52).

In particular, the increased use of non-invasive cardiovascular imaging techniques, such as cardiac $\mathrm{CT}$ scans and myocardial perfusion imaging with radionuclides, are of importance (53). Indeed, effective doses range from 1 to $20 \mathrm{mSv}$ depending on the procedure (Table I) (58). Although one cannot deny the huge health benefits of these improved diagnostic procedures, concerns are raised regarding the 'overuse' and potential associated health risks (54). For example, it has been observed that $14-22 \%$ of cardiac imaging tests are inappropriate in the US $(55,56)$.

Radiation protection of patients is not based on dose limits, but on the principle of justification that states that the benefits and risks from the use of ionizing radiation should 
Table I. Overview of typical ionizing radiation doses in cardiac imaging procedures.

\begin{tabular}{|c|c|c|c|}
\hline Examination & $\begin{array}{l}\text { Representative } \\
\text { effective dose } \\
\text { value }(\mathrm{mSv})\end{array}$ & $\begin{array}{l}\text { Range of reported } \\
\text { effective dose } \\
\text { values }(\mathrm{mSv})\end{array}$ & $\begin{array}{l}\text { Administered } \\
\text { activity } \\
(\mathrm{MBq})\end{array}$ \\
\hline Chest X-ray posteroanterior and lateral & 0.1 & $0.05-0.24$ & N/A \\
\hline Diagnostic invasive coronary angiogram & 7 & $2-16$ & N/A \\
\hline \multicolumn{4}{|l|}{ Coronary CT angiogram } \\
\hline 64-slice multidetector, retrospective gating & 12 & $9-19$ & $\mathrm{~N} / \mathrm{A}$ \\
\hline $64-$ slice multidetector, reduced tube voltage $(100 \mathrm{kVp})$ & 6 & $3-8$ & $\mathrm{~N} / \mathrm{A}$ \\
\hline 64-slice multidetector, prospective triggering & 3 & $2-4$ & $\mathrm{~N} / \mathrm{A}$ \\
\hline Dual-source high pitch & $<1$ & $<1$ & $\mathrm{~N} / \mathrm{A}$ \\
\hline 264 or 320 multidetector row CT & 4 & $2-8$ & $\mathrm{~N} / \mathrm{A}$ \\
\hline \multicolumn{4}{|l|}{ Nuclear medicine studies } \\
\hline \multicolumn{4}{|l|}{ Myocardial perfusion } \\
\hline Sestamibi (1-day) stress/rest & 12 & N/A & 1480 \\
\hline Tetrofosmin (1-day) stress/rest & 10 & N/A & 1480 \\
\hline Thallium stress/redistribution & 29 & N/A & 130 \\
\hline Rubidium-82 rest/stress & 10 & N/A & 2960 \\
\hline \multicolumn{4}{|l|}{ Myocardial viability } \\
\hline PET F-18 FDG & 14 & N/A & 740 \\
\hline Thallium stress/reinjection & 41 & N/A & 185 \\
\hline
\end{tabular}

CT, computed tomography; FDG, fluorodeoxyglucose; N/A, not applicable; PET, positron emission photography. This table has been adapted from a previous study (58).
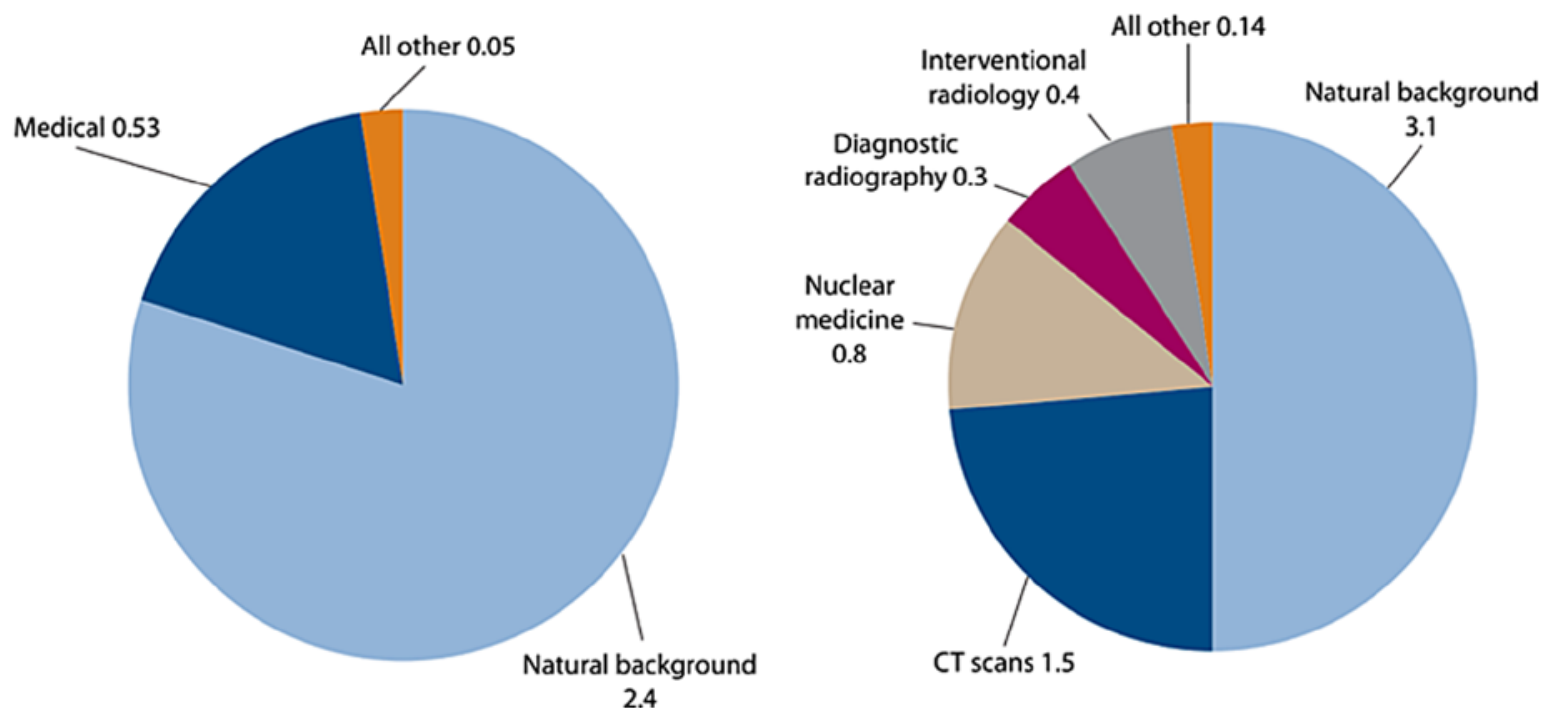

Figure 2. Average annual effective dose/person received in 1980 (left panel) and 2006 (right panel) in the United States. The large increase in the use of ionizing radiation for medical purposes, in the period 1980-2006, contributed to a total increase from $3.0 \mathrm{mSv}$ in 1980 to $6.2 \mathrm{mSv}$ in 2006 . Similar trends are observed in other industrialized countries (51).

be carefully evaluated. However, this risk/benefit balance is highly patient-dependent and the decision for the use of a specific imaging test relies on the physician's judgment. Several guidelines have been published by various societies, such as the European Society of Cardiology and the American College of Cardiology Foundation, to aid in this decision $(53,57)$. These guidelines provide information regarding the accuracy of the tests, the usefulness of the information obtained from the test, and also regarding the risks of the tests including those related to adverse radiation health effects. In addition, the implementation of informed consent, in which the possible risks are communicated to the patient and in view of his or her consent, will stimulate physicians to more carefully balance benefits and risks of a specific imaging procedure $(54,58)$. Furthermore, the development and implementation of dose-lowering techniques may be beneficial not only for the patient (59), but also for 
the physician. In addition, the identification of biomarkers of susceptibility allows screening for sensitive patients, aiding in the evaluation of the risk/benefit balance (60).

\section{Clinicalmanifestationand pathology of radiation-induced cardiovascular diseases}

Overview. As mentioned above, patients treated with radiotherapy who received doses $>40$ Gy to part of the heart may develop cardiovascular complications later on in life (5). More recently, epidemiological findings also point to an excess risk of CVD following exposure to lower doses. CVD, also commonly referred to as heart disease, comprises a broad range of different clinical manifestations. The radiation-induced clinical manifestation of CVD is dependent on various factors, such as dose, dose rate, the volume of the heart exposed, age at exposure, latency of disease, length of follow-up and other confounding factors (e.g., smoking and diet) (61). The major clinical manifestations of radiation-related CVD (i.e., pericarditis, congestive heart failure and coronary artery disease) are discussed below, together with the animal models utilized to research these radiation-related pathologies. Ionizing radiation may also cause valvular disease, arrhythmias and conduction abnormalities, although a direct causal relationship is not evidenced $(5,62)$.

Animal models. Next to epidemiology, animal models can be useful to investigate radiation-induced cardiovascular disorders. Nevertheless, it should be noted that translation to human radiation-induced atherogenic risk should be done with care. Indeed, the interaction of radiation exposure with other atherogenic risk factors is difficult to study in these animal models. For instance, gender-related differences in pro-atherogenic risk are known to have an influence, as well as lifestyle habits, such as smoking, diet and alcohol intake. Since genetic and environmental factors play a significant role in cardiovascular pathophysiology, it is difficult to match a particular disease with a single experimental model (63). Therefore, experimenters should select models that best reproduce the aspect of disease being investigated. Additional considerations of cost, infrastructure and the requirement for specialized personnel should also be taken into account. Finally, also the length of the reproductive cycle, the availability of genome-wide information and the ease of genome manipulation can influence the selection of the model.

Due to the long experience of use, the available infrastructure, the short reproductive cycle and large litters, the mouse is often the animal model of choice. In addition, the mouse has a well-known genome that is relatively easily to manipulate and more recently, infrastructures for non-invasive imaging of small animals have become available. However, normal rodents are resistant to atherosclerosis since they have low plasma levels of pro-atherosclerotic LDL. Therefore, atherosclerosisprone animal models have been developed. For example, apolipoprotein E (ApoE) $)^{-/-}$and LDL receptor ${ }^{-/-}$mouse models are commonly used $(64,65)$. ApoE is an important glycoprotein in the transport and metabolism of lipids and the lack of a functional ApoE gene leads to an altered plasma lipid profile, and the rapid development of atherosclerotic lesions $(64,65)$. Mice that lack a functional LDL receptor gene also have an altered plasma lipid profile, with elevated LDL levels. LDL receptordeficient mice will develop atherosclerosis when fed a lipid-rich diet $(64,65)$. These mouse model studies can provide valuable information regarding the understanding of the cellular and molecular pathways underlying radiation-induced development and progression of atherosclerosis.

The high-cholesterol diet rabbit models have also been used for experimental atherosclerosis (63). Cholesterol causes atherosclerotic changes in the rabbit arterial intima, very similar to human atherosclerosis. Atherosclerotic lesions also develop in normolipidemic rabbits as a result of repeated, or continuous intimal injury by catheters or balloons, or by nitrogen exposure (66).

The pig is a very good model to study CVD as it has a human-like cardiovascular anatomy (63). Pigs develop spontaneous atherosclerotic lesions. Porcine models are probably the best way to recreate human plaque instability and plaque rupture. However, they require voluminous housing with high costs, they are difficult to handle, and there are few genomic tools available for pigs.

Pericarditis. The earliest sign of radiation-related heart disease is acute pericarditis, which occurs already months after high-dose irradiation of the heart (>40 Gy). Acute pericarditis is the inflammation of the pericardium, the membrane that surrounds the heart (Fig. 3), and is characterized by the exudation of protein-rich fluid in the pericardial sac. On the long-term, this can lead to chronic constrictive pericarditis due to fibrin deposition, causing a thickened, rigid pericardial sac $(2,67)$. The development of acute pericarditis has also been observed in rabbits, rats and dogs after single doses to the heart of 16-20 Gy (68-70). These experimental studies showed a threshold dose of approximately 15 Gy with a steep dose-response relationship (incidence of $100 \%$ at $20 \mathrm{~Gy}$ ). Since 1970 , advances in radiotherapy treatments have led to a significant reduction in both the dose and the volume of the heart exposed (3). Therefore, radiation-induced pericarditis is uncommon these days.

Coronary artery disease. The obstruction of the blood flow in coronary arteries, responsible for blood supply to the heart, is referred to as coronary artery disease (9). Mild obstruction due to narrowing of the coronary arteries leads to angina (discomfort due to ischemia of the heart muscle), whereas severe blockage leads to myocardial infarction (heart attack), which on its turn leads to acute heart failure. Atherosclerosis is the major underlying pathogenesis causing coronary artery disease. It can be described as a chronic inflammatory disease of the arterial wall in which the build-up of plaques in the intima impairs normal vascular functioning (Fig. 4). These plaques are characterized by the accumulation of lipids and fibrous elements (71). The development and progression of atherosclerosis is a complex process with many players. The presence of plaques leads to narrowing of the artery and, upon rupture of a plaque, even to blockage of the artery (72). Nowadays, coronary artery disease is considered the major cardiovascular complication in patients that have received radiotherapy for thoracic malignancies (73).

The effect of ionizing radiation on the development and progression of atherosclerosis has been investigated in various animal models, which has been reviewed (9). For example, 

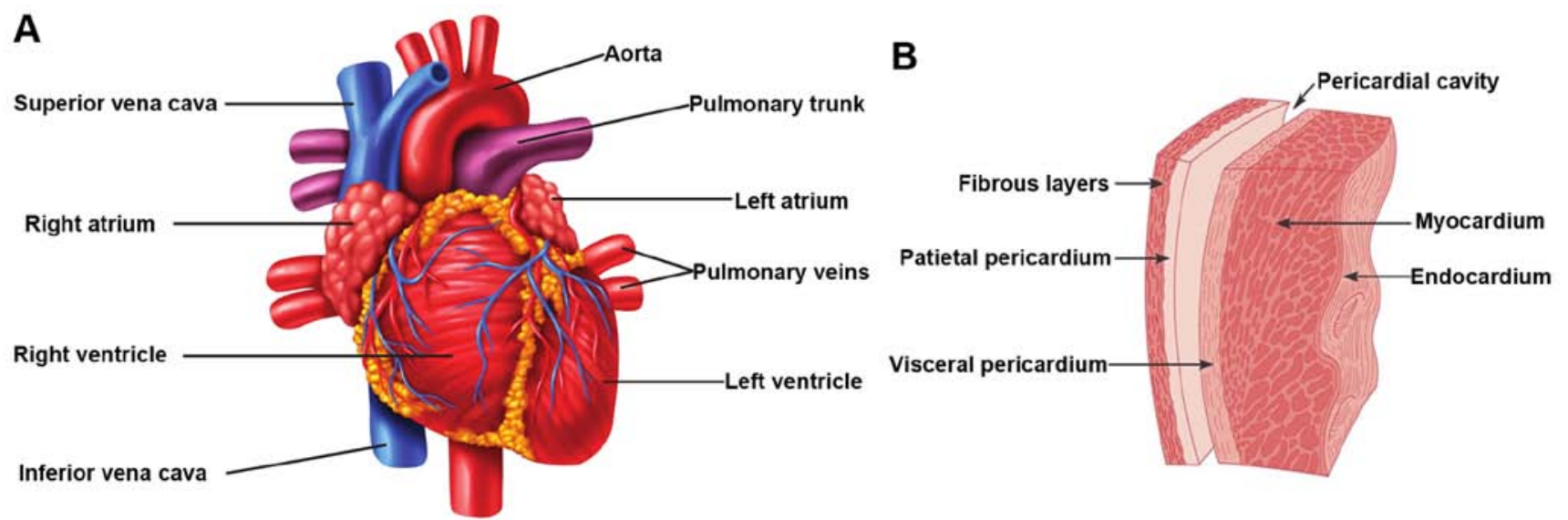

Figure 3. Overview of the heart anatomy. (A) Illustration of the external anatomy with the major cardiac veins and arteries. (B) More detailed illustration of the pericardial sac that surrounds the heart.

A

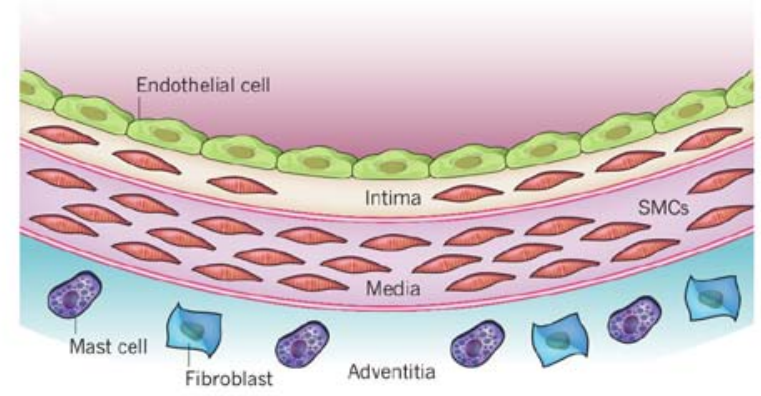

C

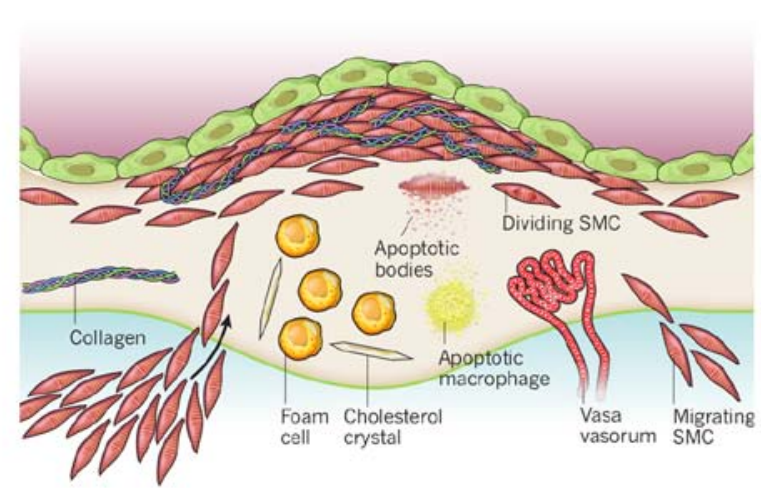

B

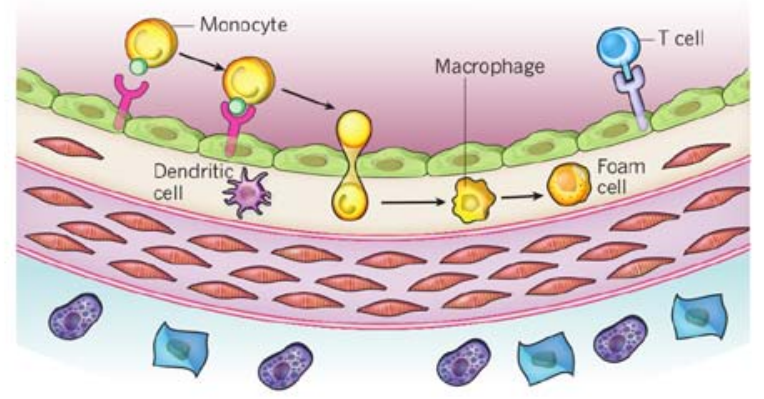

D

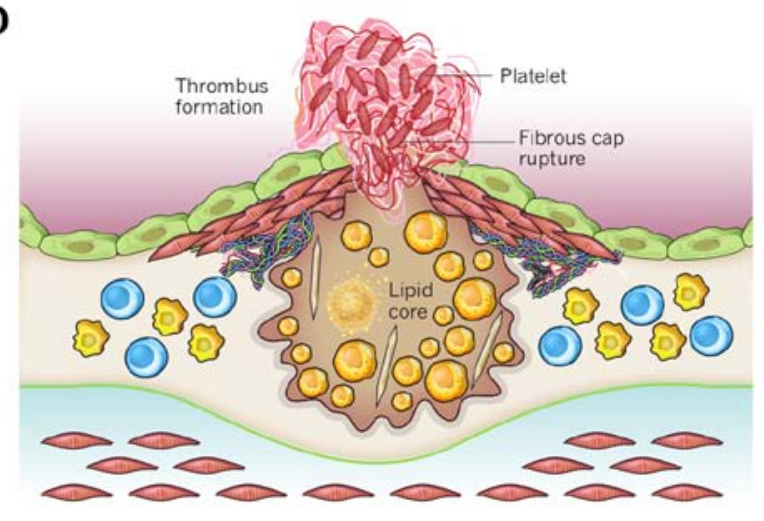

Figure 4. Schematic overview of the development of an atherosclerotic lesion. In all steps, inflammation plays an important role. (A) A healthy artery with a well-functioning intact endothelium, a tunica intima, media and adventitia. VSMCs are mainly found in the tunica media but also in the tunica intima. (B) One of the initiating steps is the expression of adhesion molecules on the endothelium and the subsequent attraction of inflammatory blood cells (mainly monocytes). These monocytes will transmigrate to the intima where they will maturate to macrophages which will then transform to foam cells upon the uptake of ox-LDL. (C) Further progression to an atherosclerotic plaque includes the transmigration of VSMCs from the tunica media into the intima and the proliferation of VSMCs in the intima. There is also an enhanced production of extracellular matrix molecules, such as collagen, elastin and proteoglycans. Macrophages, foam cells and VSMCs can die, and released lipids will accumulate into the central region of the plaque, also denoted the lipid or necrotic core. (D) When a plaque ruptures it will induce thrombosis which is the major complication. The blood component will come in contact with the tissue factors present in the interior of the plaque triggering the formation of a thrombus which will hamper or even obstruct blood flow. The figure is based on a previous study (167). VSMCs, vascular smooth muscle cells; ox-LDL, oxidized low-density lipoprotein.

Stewart et al examined the development and progression of atherosclerotic lesions in $\mathrm{ApoE}^{-/}$mice after single-dose irradiation (14 Gy) of the neck region (74). There was no major increase in the total plaque burden in the exposed carotid arteries, although the quality of the plaques was changed, acquiring inflammatory characteristics. Indeed, the plaques showed a macrophage-rich core, low collagen content and intraplaque haemorrhage, which are known to render human atherosclerotic plaques unstable and prone to rupture. They also observed the presence of atypical swollen endothelial cells. It is hypothesized 


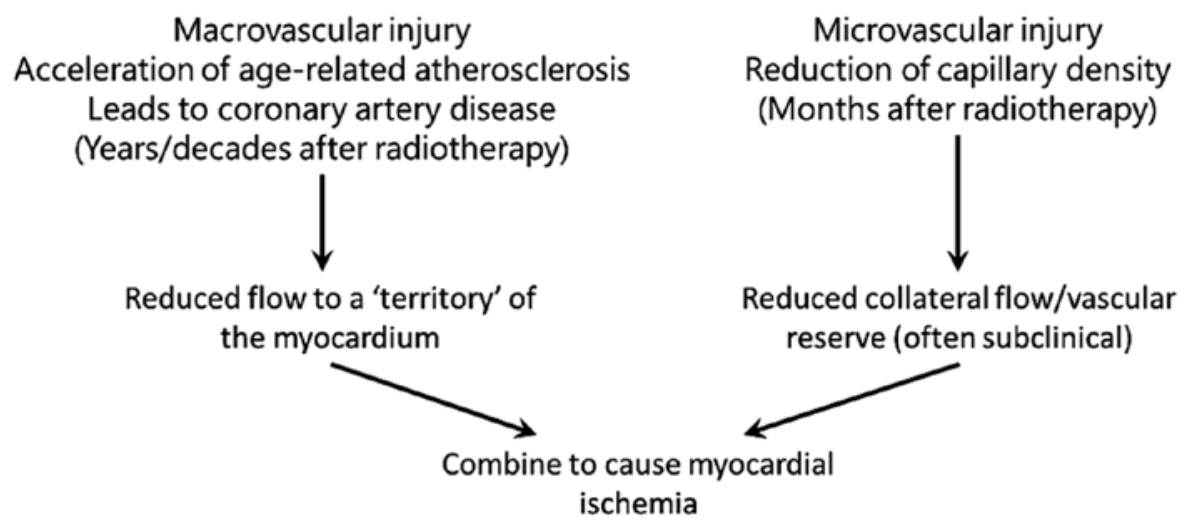

Figure 5. A theoretical overview of how radiation-induced macrovascular and microvascular pathologies can interact to cause myocardial ischemia, which may ultimately develop into clinical heart disease. The figure has been adapted from a previous study (5).

that radiation-induced changes in endothelial function together with radiation-induced endothelial cell death and the exposure of thrombotic elements of the underlying subendothelium leads to chronic inflammation and the development of a vulnerable plaque (74). Gene expression profiling of $\mathrm{ApoE}^{-/-}$mice exposed to an acute dose of 16 Gy also revealed the upregulation of inflammation-related pathways (75). Further research by the same group revealed that a more clinically relevant fractioned irradiation scheme (20x2 Gy in 4 weeks) also predisposed to the formation of an inflammatory plaque (76). Remarkably, acute lower dose irradiation $\left(8 \mathrm{~Gy}\right.$ ) of $\mathrm{ApoE}^{-/-}$mice did not predispose to an inflammatory plaque, but did accelerate the development of atherosclerosis, as demonstrated by an increased number of plaques. Overall, the authors concluded that exposure to highdose ionizing radiation accelerates the atherosclerotic process in the presence of other risk factors (e.g., high-fat diet), and predisposes to the development of a vulnerable inflammatory plaque prone to rupture (9).

With low doses and dose rates of radiation the response warrants further investigation. Mitchel et al exposed $\mathrm{ApoE}^{-1-}$ mice to low doses of radiation $(0.025-0.5 \mathrm{~Gy})$ at either the high $(150 \mathrm{mGy} / \mathrm{min})$ or low $(1 \mathrm{mGy} / \mathrm{min})$ dose rate (77). The mice were exposed at an early stage of atherosclerotic disease ( 2 months old) or at a late stage of atherosclerotic disease ( 8 months old). Doses of 0.025-0.050 Gy, administered at both the low- and high-dose rate, induced a protective effect by attenuating the formation of new lesions and the increase in the size of existing lesions, in mice exposed at an early stage. High-dose rate exposure however, increased the progression of lesion severity. The effect for mice exposed at a late stage of atherosclerotic disease with low-dose rate was similar as that for mice exposed at an early stage. On the other hand, highdose rate exposures protected against the progression of lesion severity, opposite to what was observed in mice exposed at an early stage. Additional experiments with $\mathrm{ApoE}^{-/-{ }^{-/}}$mice with reduced p53 functionality $\left(\operatorname{Trp} 53^{+-}\right)$revealed an important role for p53 in atherosclerosis progression (73). For example, protective effects of low-dose radiation delivered at both low and high dose rate were observed in Trp53 normal mice exposed at a late stage of atherosclerotic disease. On the other hand, with the same irradiation procedure, detrimental effects were observed in $\operatorname{Trp} 53^{+-}$mice exposed at a late stage of atherosclerotic disease. Overall, these findings raised the importance of dose-rate effects and p53 functionality on the development of atherosclerosis. Furthermore, their findings point out that a linear extrapolation of the effects at high doses to low doses is not appropriate.

In addition, the effects of chronic low-dose rate vs. acute exposures were evaluated in female $\mathrm{ApoE}^{-/-}$mice (60 days) that were chronically irradiated for 300 days with gamma-rays at two different dose rates ( 1 and $20 \mathrm{mGy} / \mathrm{day})$, with total accumulated doses of 0.3 or 6 Gy (78). For comparison, age-matched $\mathrm{ApoE}^{-/-}$females were acutely exposed to the same doses and sacrificed 300 days post-irradiation. Mice acutely exposed to 0.3 or 6 Gy showed increased atherogenesis compared to the age-matched controls, and this effect was persistent. When the same doses were delivered at the low-dose rate over 300 days, again a significant impact on global development of atherosclerosis was observed, although at $0.3 \mathrm{~Gy}$ effects were limited to the descending thoracic aorta. These data suggest that a moderate dose of $0.3 \mathrm{~Gy}$ can have persistent detrimental effects on the cardiovascular system, and that a high dose of 6 Gy poses high risks at both the high- and low-dose rates. The results were clearly non-linear with dose, suggesting that lower doses may be more damaging than predicted by a linear dose response.

Darby et al formulated two hypotheses for biological mechanisms that lead to increased morbidity and mortality from coronary artery disease following radiation exposure (5). The first hypothesis states that radiation interacts with the pathogenesis of age-related atherosclerosis, as such accelerating the development of atherosclerosis. The second hypothesis is that radiation increases the lethality of agerelated myocardial infarction by decreasing the heart tolerance to acute infarctions as a result of microvascular damage in the myocardium. These hypotheses do not stand alone, and both macro- and microvascular effects most likely act together to produce clinical heart disease (Fig. 5).

Finally, Le Gallic et al investigated the effects of a chronic internal exposure to ${ }^{137} \mathrm{Cs}$ on atherosclerosis in predisposed $\mathrm{ApoE}^{-/-}$mice (79). Mice were exposed daily to $0,4,20$ or $100 \mathrm{kBq} / 1{ }^{137} \mathrm{Cs}$ in drinking water, corresponding to range of concentrations found in contaminated territories, for 6 or 9 months. The results suggest that the low-dose chronic exposure of ${ }^{137} \mathrm{Cs}$ in $\mathrm{ApoE}^{-/-}$mice enhances atherosclerotic lesion stability by inhibiting pro-inflammatory cytokine and 
matrix metalloproteinase (MMP) production, resulting in collagen-rich plaques with greater smooth muscle cell and less macrophage content.

Congestive heart failure. Congestive heart failure is described by a compromised blood pumping function of the heart, due to a reduced capacity of the heart muscles, causing underperfusion of the body tissues. The underlying pathologies are various and include IHD, hypertension, valvular heart disease, cardiomyopathies and congenital heart disease (80). Rats that received single doses of at least $15 \mathrm{~Gy}$ to the heart have been shown to develop congestive heart failure within their normal lifespan (70). Further radiobiological research has revealed an important role for radiation-induced decrease in capillary density. Areas of decreased capillary density in the heart are characterized by focal loss of the endothelial cell marker, alkaline phosphatase (81). The progressive reduction of capillary density leads to ischemic necrosis, fibrosis and the death of cardiac myocytes (muscle cells) in these areas. This myocardial degeneration is associated with the first symptomatic signs of congestive heart failure, a slight decrease in left ventricle ejection fraction (2). This reduced cardiac function is maintained in a steady-state for a certain period, due to in vivo compensatory mechanisms, and fatal congestive heart failure is only observed on the long-term (82). Indeed, in ex vivo experiments, cardiac function has been shown to deteriorate more rapidly (83).

Myocardial damage has also been observed with lower doses. For instance, mild alterations in cardiac function in $\mathrm{ApoE}^{-/}$mice following exposure to $2 \mathrm{~Gy}$ have been observed, which however did not deteriorate over time (84). Histological examination revealed functional damage to the microvasculature as indicated by a focal loss of alkaline phosphatase. More recently, Monceau et al exposed the hearts of $\mathrm{ApoE}^{-/-}$and wild-type mice to doses of 0.2 Gy (85). Mild but significant alterations in cardiac function were observed in both mouse strains following exposure to $0.2 \mathrm{~Gy}$. The progression of cardiac dysfunction remained, however, stable over the whole study period (60 weeks), suggesting the occurrence of compensatory mechanisms. Whereas in $\mathrm{ApoE}^{-/-}$mice cardiac damage was the consequence of reactive fibrosis in response to inflammatory signalling, this was the consequence of reparative fibrosis induced by the loss of cardiac myocytes in wild-type mice. Overall, $\mathrm{ApoE}^{-/}$mice were more radiosensitive. This implies that atherosclerosis predisposition enhances and accelerates the structural deterioration of the heart following exposure to low doses of ionizing radiation, and can thus be considered as a risk factor.

\section{Molecular and cellular mechanisms underlying the observed radiation-induced cardiovascular disorders}

The mechanism through which radiation causes heart disease is at present unknown, but it acts, at least in part, by causing or promoting atherosclerosis. Atherosclerosis is a multifactorial disease, resulting from interactions between genetic and environmental factors which may be modified by radiation exposure. For radiation doses $>1-2 \mathrm{~Gy}$, in vitro and in vivo studies have shown that several mechanisms may play a relevant role in radiation-induced cardiovascular effects $(3,86-88)$. These effects include endothelial dysfunction, inflammation, oxidative stress, alterations in coagulation and platelet activity, DNA damage, senescence and cell death. On the contrary, low-dose exposure produces both protective and detrimental effects, suggesting that multiple mechanisms may influence radiation-induced atherosclerosis (42).

Need for experimental studies, particularly in the low-dose region. Due to reasons of statistical power, in exposure to doses $<0.5 \mathrm{~Gy}$, an increased cardiovascular risk cannot be evidenced by epidemiology alone, and a better understanding of the underlying biological and molecular mechanisms is needed. If one proves that there is an increased risk of CVD following low-dose exposure, it may have a considerable impact on current low-dose health risk estimates.

In contrast to cancer and hereditary effects, knowledge of the underlying biological mechanisms for other radiationrelated non-cancer effects in the moderate and low-dose range is limited and is assumed to be different from high-dose exposure. Therefore, research to understand the mechanisms is urgently necessary [Multidisciplinary European Low Dose Initiative, Strategic Research Agenda 2015, http://www.melodi-online. $\mathrm{eu} / \mathrm{J}$. Further research is essential to elucidate the low-dose effects on the cardiovascular system, and the impact on CVD risk. This is, however, not straightforward due to the subtlety of low-dose effects and the, most likely, little impact on clinical outcome. Apart from the integration of epidemiology and biology, as mentioned above, pure radiobiological studies are needed. These include mechanistic studies and in vitro studies focusing on the elucidation of molecular signaling pathways and further in vivo studies. In these studies, attention should be paid, not only to dose, but also to dose-rate, fractionated exposures and radiation quality.

The role of inflammation. As indicated in Fig. 6, ionizing radiation acts on the atherosclerotic process by enhancing pro-inflammatory signalling, as reviewed previously $(3,89)$. Atherosclerotic plaques are formed by the migration of inflammatory cells from the bloodstream into the intima where they transform to foam cells. The endothelial expression of adhesion molecules plays an important role in this process. Radiation has been shown to upregulate E-selectin, intercellular adhesion molecule (ICAM)-1 and vascular cellular adhesion molecule (VCAM)-1 following irradiation of endothelial cells, in a time- and dose-dependent manner (3). For instance, the exposure of endothelial cells to $5 \mathrm{~Gy}$ has been shown to induce an increase in ICAM-1 and E-selectin expression $6 \mathrm{~h}$ after irradiation (90). Platelet endothelial cell adhesion molecule (PECAM)-1, ICAM-1/2 and VCAM-1 were also observed to increase in mouse heart cells 10 weeks after local thorax irradiation with 8 Gy (91). Interestingly, ICAM-1 and VCAM-1 remained upregulated 20 weeks after irradiation. The transcription factor, nuclear factor- $\mathrm{KB}(\mathrm{NF}-\mathrm{\kappa B})$, is involved in the radiation-induced upregulation of adhesion molecules (92). Apart from the induction of adhesion molecules, the levels of cytokines such as interleukin (IL)-6 and IL-8, and other inflammatory molecules, such as transforming growth factor- $\beta$ (TGF- $\beta$ ), were shown to increase after high and moderate irradiation $(93,94)$. In addition, the Japanese atomic bomb survivors' cohort showed signs of a general increased state of inflammation, with increased levels of IL-6 and C-reactive 


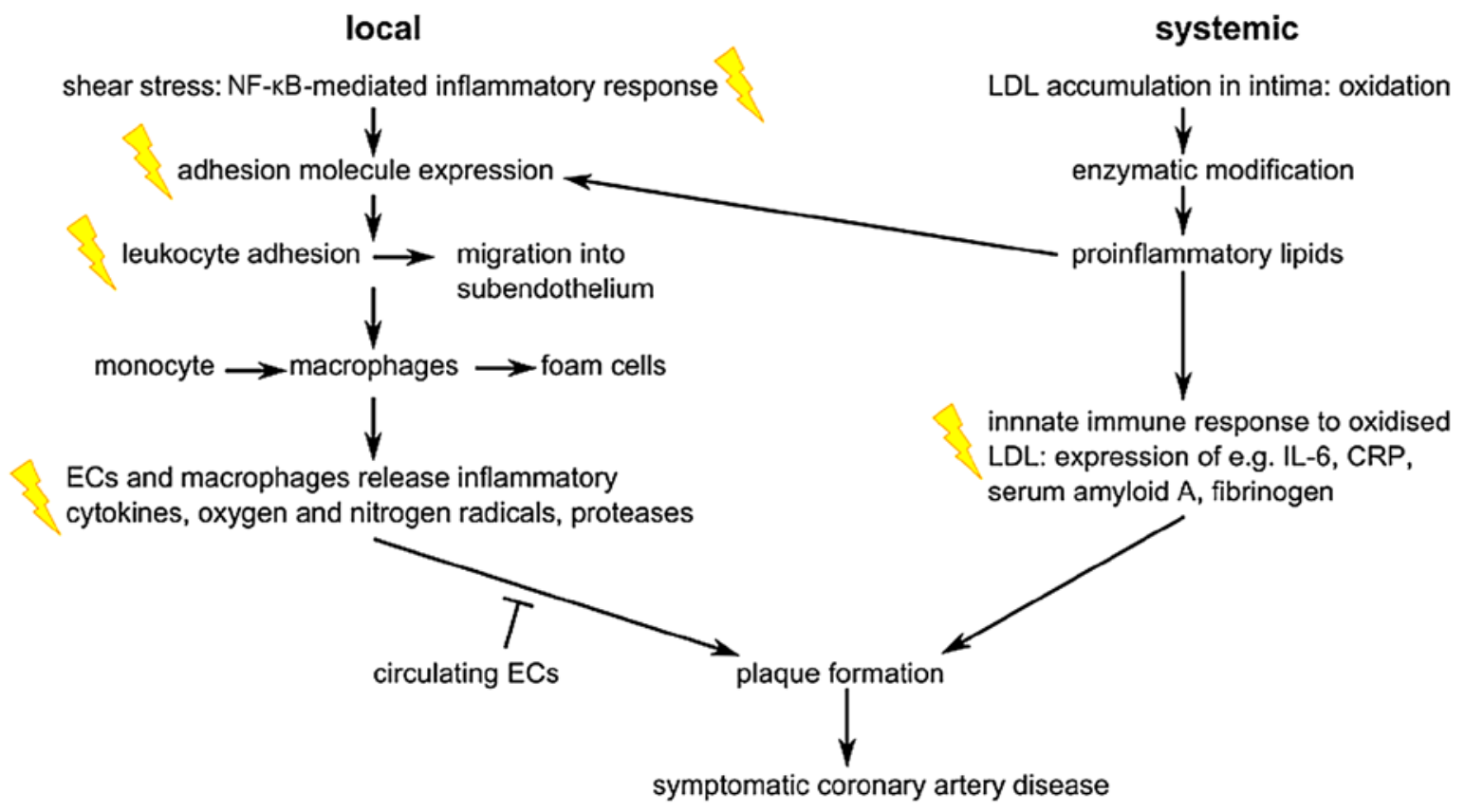

Figure 6. Overview of the major steps in the pathogenesis of coronary artery disease at the local and systemic level. Flashes indicate events that were also observed after radiation exposure, and which are mainly related to inflammation. ECs, endothelial cells; LDL, low-density lipoprotein; IL-6, interleukin-6; CRP, C-reactive protein. The figure has been adapted from a previous study (3).

protein (CRP) (95). In addition to pro-inflammatory responses, there is evidence of pro-thrombotic changes after irradiation of the endothelium. For example, several in vitro and in vivo studies have demonstrated increased levels of von Willebrand factor (VWF) and decreased levels of the anticoagulant, thrombomodulin $(3,96)$.

Inflammation was also predicted from a proteomic study as an immediate biological response in the cardiac tissue of wildtype mice exposed to total body irradiation with 3 Gy gamma radiation (97). Validated proteomic data concerning cardiac microvascular endothelial cells that were isolated from wildtype mice that received local X-ray heart doses of 8 or 16 Gy and that were sacrificed after 16 weeks also strongly suggested enhanced inflammation as the main causes of radiation-induced long-term vascular dysfunction (98).

There is clinical evidence for anti-inflammatory responses of low-dose radiation exposure in individuals who experience inflammatory diseases. Indeed, for decades, low-dose radiotherapy has been used for the treatment of benign inflammatory diseases $(99,100)$. However, due to the debate regarding possible cancer and non-cancer risks of low-dose radiation exposure, the use of low-dose radiotherapy has become unfashionable nowadays (101). In vitro experimental studies have confirmed the anti-inflammatory effects of activated endothelial cells after X-irradiation. Indeed, no induction of ICAM-1 and E-selectin was observed up to $24 \mathrm{~h}$ after exposure to 0.3 and $1 \mathrm{~Gy}$, and was even decreased $4 \mathrm{~h}$ after irradiation (90). This results in a decreased mononuclear cell adhesion onto the endothelium $(90,102)$.

\section{Endothelium as a critical target in radiation-related CVD} Endothelium is the safeguard of normal vascular functioning. The endothelium is a single layer of cells that lines the interior of the vascular system and has thus a strategic position between the blood and the surrounding tissues. Endothelial cells are involved in a wide range of physiological processes, such as the regulation of vascular tone, vascular permeability, blood coagulation/fibrinolysis and inflammation, which are required to maintain proper vascular functioning (Fig. 7) (103). Endothelial dysfunction has been observed in patients with atherosclerosis and in patients that exhibit CVD risk factors such as smoking, dyslipidaemia, obesity and diabetes mellitus (104), and is considered one of the first indicators of future cardiovascular morbidity and mortality (105-108). It should be noted that the endothelium is regarded as a critical target for radiationinduced CVD.

The endothelium displays phenotypical and functional heterogeneity depending on the vascular bed and tissue it is situated in $(109,110)$. The major function of arteries and veins is the circulation of blood through the body. Capillaries, on the other hand, are the major exchange vessels and the capillary endothelium is thus very thin and usually fenestrated to ensure the optimal diffusion of oxygen and nutrients between the blood and underlying tissue (110). Arterial endothelial cells are sensitive to disrupted flow at branching points and curvatures in the arterial system, which are, consequently, 'hotspots' for inflammation, coagulation and atherosclerosis (110). A healthy arterial endothelium mediates vasodilatation and actively suppresses thrombosis, vascular inflammation and inhibits vascular smooth muscle cell proliferation and migration (111).

CVD risk factors associated with endothelial dysfunction include hypertension, smoking, dyslipidaemia and aging. A common underlying cellular mechanism leading to endothelial dysfunction is oxidative stress (112). Oxidative stress is defined as an imbalance between the generation of reactive oxygen species (ROS) (Fig. 8) and the activity of enzymatic and non-enzymatic antioxidant systems (113). At physiological levels, ROS are important signalling molecules; however, at 

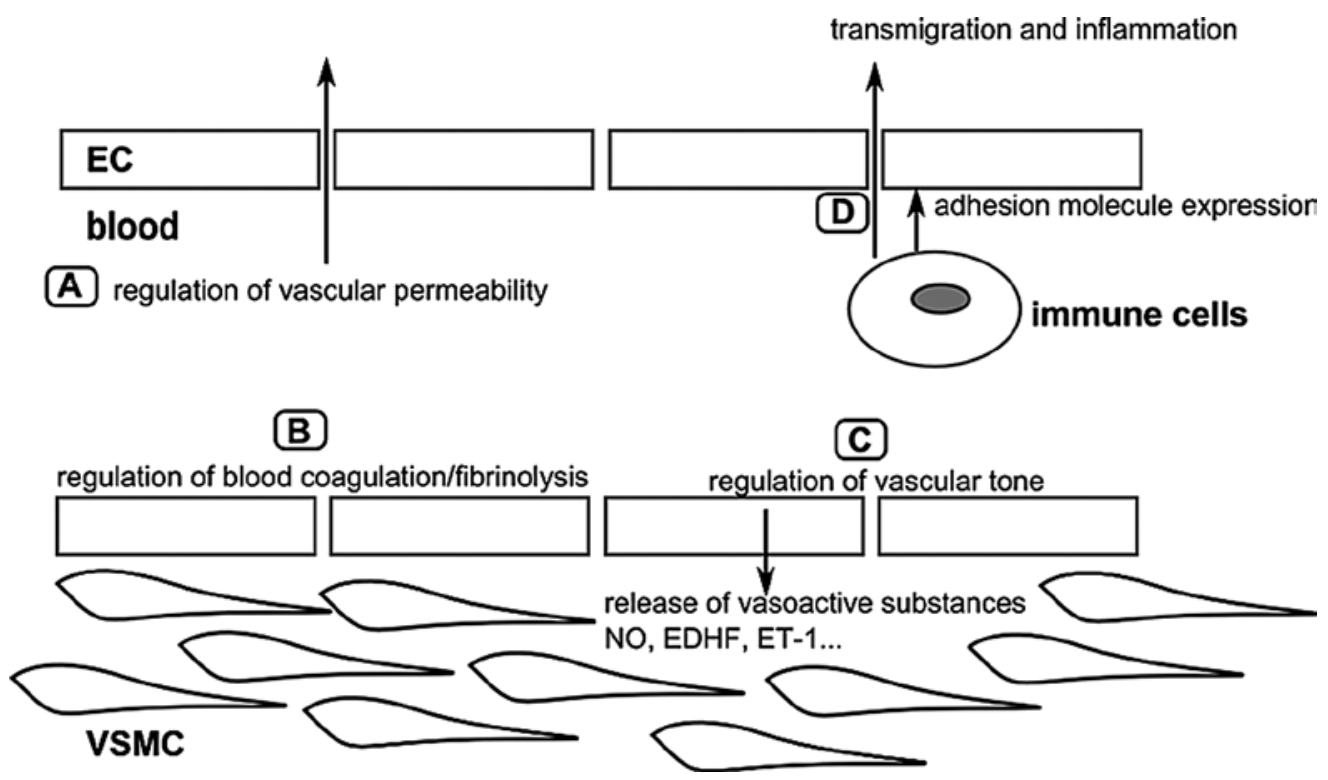

Figure 7. Overview of the major physiological functions of the arterial endothelium. (A) The endothelium forms a selective barrier regulating the solute flux and fluid permeability between the blood and surrounding tissues (105). (B) The formation of a thrombus or blood clot is referred to as coagulation and the breakdown of a thrombus is referred to as fibrinolysis. Normal endothelium has anti-thrombotic and pro-fibrinolysis properties, and actively represses platelet adhesion and aggregation. Vessel damage or exposure to pro-inflammatory molecules will shift the balance towards more pro-thrombotic/anti-fibrinolysis actions $(106,107)$. (C) To regulate vascular tone, the endothelium releases various vasodilatory factors such as NO and EDHF, or vasoconstrictive factors such as ET-1 which will modify VSMC function (108). (D) In the case of inflammation, endothelial permeability will be increased. Endothelial cells will also recruit immune cells via the expression of adhesion molecules, and mediate their transmigration towards the inner vascular wall (107). The figure is based on a previous study (103). ECs, endothelial cells; VSMCs, vascular smooth muscle cells; NO, nitric oxide; EDHF, endothelium-derived hyperpolarizing factor; ET-1, endothelin-1.

higher concentrations, ROS cause cellular injury by inducing oxidative damage to DNA, lipids and proteins, and may result in cell death (114). Apart from cellular damage, oxidative stress leads to a decrease in nitric oxide bioavailability, premature senescence and mitochondrial dysfunction in endothelial cells.

In vitro endothelial models. The recognition of the endothelium as a central regulator of the cardiovascular system significantly enhanced endothelium-related research. One of the milestones was the first successful isolation and subsequent cultivation and characterization of endothelial cells in vitro, in the 1970s (109). Jaffe et al (115) and Gimbrone et al (116) reported independently the isolation of endothelial cells from human umbilical veins [human umbilical vein endothelial cells (HUVECs)]. Since then, many studies have relied on the use of HUVECs as they are relatively easy to obtain. Although originating from large vessels, HUVECs are unique since they exhibit endothelial properties that are intermediate between those of large vessels (e.g., the aorta) and those of the microvasculature (117). EA.hy926 cells, which are an immortalized derivate of HUVECs, are commonly used as well (118). However, it should be taken into account when using these cells as models for studying the endothelium radiation response, that there is a differential response to ionizing radiation in primary and immortalized endothelial cells. For example, EA.hy926 cells are more sensitive to the induction of apoptosis and double-strand breaks (DSB) in comparison to the same dose of ionizing radiation administered to HUVECs (119).

It should be noted that in vitro endothelial cell models are not limited to HUVECs and EA.hy926 cells. Endothelial cells may be isolated from other sources in the human body, such as the dermal microvasculature, coronary arteries and the pulmonary vasculature. However, these are usually not easy to obtain and at best only a small amount of material is available. In addition, these primary cell cultures cannot be kept in long-term cultures as they begin to lose their endothelial cell characteristics. Therefore, immortalized derivatives of these primary cells have been established; for example, EA.hy926 cells are a derivate of HUVECs. Immortalized cells are characterized by their ability to overcome senescence and can be kept in culture for long periods of time (120). These immortalized derivatives, however, also exhibit tumour cell characteristics (121). For instance, immortalized human coronary artery endothelial cells [transfected with human telomerase reverse transcriptase (hTERT)] showed $40 \%$ of aneuploidy at a low passage number and $100 \%$ of aneuploidy at a high passage number (121).

Of course, in vitro endothelial models, although useful, are not fully representative for the in vivo situation. Yet, advances have been made, such as the development of co-culture models where endothelial cells are cultured with vascular smooth muscle cells to study the atherosclerotic process $(122,123)$. In addition, 3-D cultures, where endothelial cells are grown in a matrix allowing the formation of tubule-like structures are increasingly used to study angiogenesis $(124,125)$. A recent review described in detail the use of these co-culture and 3 -D culture models in radiation research (126).

The effect of ionizing radiation on the endothelium. Gaining insight into the endothelial response to ionizing radiation exposure is not only of importance for understanding the development of radiation-related CVD, but also for optimizing cancer treatment. For instance, adverse reactions in the surrounding healthy tissue of the tumour are related to 


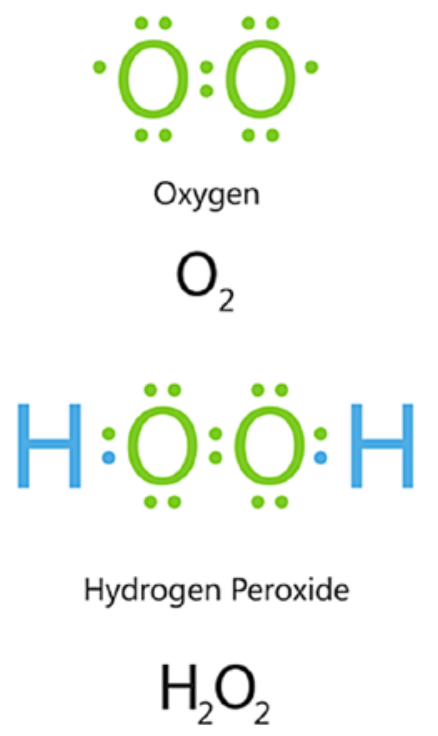

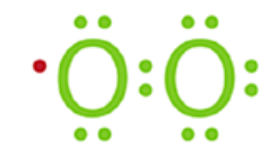

Superoxide anion

$$
\cdot \mathrm{O}_{2}^{-}
$$

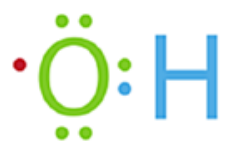

Hydroxyl radical

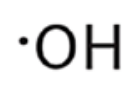

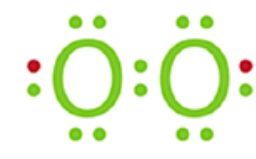

Peroxide

$$
\mathrm{O}_{2}^{-2}
$$

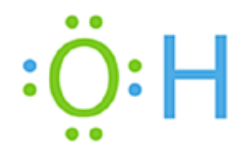

Hydroxyl ion

Figure 8. Electron structures of common ROS. Below each structure, its name and chemical formula are given. $\bullet$ represents an unpaired electron. ROS, reactive oxygen species.

the radiation-response of the microvasculature in the tissue of concern. In addition, tumour growth is highly dependent on an abundant blood supply, which is maintained by a rich vascular network (127). The tumour vasculature thus became a potential target in radiotherapy (128). Understanding the effects of radiotherapy on the tumour endothelium can improve treatment regimes. Since the tumour endothelium differs in many aspects to the normal endothelium (129), this is not in the scope of this review.

Below, an overview is given of classical cellular radiation effects and how these may affect endothelial functioning. Next, the impact of ionizing radiation on mitochondrial function and on senescence is discussed. Finally, attention is paid to the contribution of new technologies, such as high throughput transcriptomic profiling, allowing a better understanding of the underlying molecular signalling pathways:

i) DNA-targeted effects. Ionizing radiation is known to induce a wide range of DNA lesions, such as base damage, DNA crosslinks, single-strand breaks and DSB in a direct manner, but also indirectly through the formation of ROS $(130,131)$. Upon DNA damage, a DNA damage response is initiated and the cells will activate cell cycle checkpoints which can slow down or stop cell cycle progression (132). This gives cells the time to repair the damaged DNA or to prevent division when chromosomes are damaged or incompletely replicated. If the cells fail to repair the DNA, they can go into apoptosis (133).

In particular, DSB will lead to a high lethality of the affected cells (134). At the site of DSB damage, the histone $\mathrm{H} 2 \mathrm{AX}$ is phosphorylated (referred to as $\gamma-\mathrm{H} 2 \mathrm{AX}$ ) by kinases, such as ataxia telangiectasia mutated (ATM) and ataxia telangiectasia and Rad3-related protein (ATR), resulting in the formation of $\gamma$-H2AX foci (130). These foci will recruit DNA repair proteins to the DSB sites. It has been shown that there is a 1:1 relationship between the amount of DSB and the $\gamma-\mathrm{H} 2 \mathrm{AX}$ foci formed (135). Visualization and quantification of $\gamma-\mathrm{H} 2 \mathrm{AX}$ foci has become a standard in assessing radiation-induced DNA damage.
Irreparable DSB can cause cellular apoptosis, or premature senescence (described below). Endothelial apoptosis has implications on both the micro- and macrovascular. Namely, endothelial cell death in the microvasculature leads to a decrease in capillary density. In addition, endothelial apoptosis has been related to the development of atherosclerosis $(136,137)$ as it may compromise the regulation of vascular tone, and increase the proliferation and migration of vascular smooth muscle cells (VSMCs) (138). Furthermore, thrombosis, the major complication of atherosclerosis, can be triggered by endothelial cell death (137). It should be noted that radiationinduced endothelial cell apoptosis is not solely a consequence of DNA damage. Indeed, ionizing radiation can act on the cellular membrane of endothelial cells as well, generating ceramide which can induce apoptosis (139).

Whereas high doses are known to induce the apoptosis of endothelial cells (140), less is known about the effect of low doses. There are indications that, regarding apoptosis, endothelial cells display a non-linear dose relationship. Rödel et al demonstrated a discontinuous induction of apoptosis with a relative maximum at 0.3 and $3 \mathrm{~Gy}$ and a relative minimum at $0.5 \mathrm{~Gy}$ in endothelial cells stimulated with tumor necrosis factor (TNF)- $\alpha$ (141). Another study showed no increase in apoptotic endothelial cells following exposure to $0.2 \mathrm{~Gy}$, but only following exposure to $5 \mathrm{~Gy}$ (142). In a different study, a subtle but a significant increase in DSBs was observed in HUVECs and EA.hy926 cells 30 min after exposure to $0.05 \mathrm{~Gy}$. In addition, irradiation with 0.05 and $0.1 \mathrm{~Gy}$ induced relatively more DSB/Gy in comparison to 0.5 and 2 Gy. Furthermore, a dose-dependent increase in apoptotic cells was observed, down to 0.5 Gy in HUVECs and 0.1 Gy in EA.hy926 cells (119).

ii) Radiation-induced mitochondrial dysfunction and metabolic changes. There is a great deal of interest in radiationinduced mitochondrial dysfunction, seeing the implications it has on CVD (143). Mitochondrial dysfunction is closely related to oxidative stress, being both a target and a source of ROS. Initially, ionizing radiation causes the formation of water 
radiolysis products, including hydroxyl radicals $\left({ }^{\circ} \mathrm{OH}\right)$, hydroperoxyl radicals $\left(\mathrm{HO}_{2}{ }^{\circ}\right)$ and hydrogen peroxide $\left(\mathrm{H}_{2} \mathrm{O}_{2}\right)$ (Fig. 8). These are unstable and disappear within $<10^{-3} \mathrm{sec}$, apart from $\mathrm{H}_{2} \mathrm{O}_{2}$ (144). However, following irradiation, oxidative stress is observed after longer time periods due to an increase in the endogenous cellular production of ROS (145). The mitochondria are believed to be the major source of these radiation-induced secondary ROS, although other sources may contribute as well. For instance, Leach et al (147) demonstrated that, between 1 and $10 \mathrm{~Gy}$, the amount of ROS-producing cells increased with the dose, which they suggested was dependent on the radiationinduced propagation of mitochondrial permeability transition via a $\mathrm{Ca}^{2+}$-dependent mechanism (146).

Since the mitochondria, in particular mitochondrial DNA (mtDNA), are also a critical target of ROS, measurements of mtDNA damage have been used to determine the deleterious effects of ionizing radiation. The increased accumulation of common deletion (CD) following exposure to ionizing radiation has been detected in various studies (148-150). The measurement of $\mathrm{CD}$ by quantitative (real-time) polymerase chain reaction (PCR) has been proposed as a sensitive marker to detect low levels of oxidative damage to the mtDNA (148). An increased accumulation of the $\mathrm{CD}$ has been observed in several human fibroblast cell lines following exposure to doses as low as $0.1 \mathrm{~Gy}$ (150). Interestingly, increased accumulation of the CD was also observed in bystander cells, i.e., cells that were cultured in conditioned medium derived from 0.1 Gy-irradiated cells.

However, the question of whether low doses of ionizing radiation have an impact on mitochondrial function has not been fully resolved yet. For instance, an in vivo study by Barjaktarovic et al investigated the effects in vivo of 0.2 and 2 Gy local heart irradiation on cardiac mitochondria (151). In another study of theirs, four weeks after exposure, cardiac mitochondria were isolated from C57BL/6N mice and subjected to proteomic and functional analysis. Whereas with $2 \mathrm{~Gy}$ both functional impairment of mitochondria and alterations in the mitochondrial proteome were observed, only a few alterations in the mitochondrial proteome and no effect on mitochondrial function was observed with $0.2 \mathrm{~Gy}$. After 40 weeks, the respiratory capacity of irradiated C57BL/6 cardiac mitochondria was significantly reduced at 40 weeks (152). In parallel, protein carbonylation was increased, suggesting enhanced oxidative stress. In addition, considerable alterations were found in the levels of proteins of the mitochondria-associated cytoskeleton, respiratory chain, ion transport and lipid metabolism. Highdose radiation induced similar, but less pronounced effects in the mitochondrial proteome of $\mathrm{ApoE}^{-/-}$mice after 40 weeks upon local heart $\mathrm{X}$-irradiation. In $\mathrm{ApoE}^{-/}$mice, no significant change was observed in mitochondrial respiration or protein carbonylation. The dose of $0.2 \mathrm{~Gy}$ had no significant effects on cardiac mitochondria.

Alterations in cardiac proteins involved in lipid metabolism and oxidative phosphorylation were shown in a proteomic study of mice that received local heart irradiation with X-ray doses of 8 and 16 Gy and were sacrificed at week 16 after exposure (153). Ionizing radiation markedly altered the phosphorylation and ubiquitination status of peroxisome proliferator-activated receptor (PPAR) $\alpha$, a transcriptional regulator of lipid metabolism in heart tissue with a possible role in the development of CVD. This was reflected as a decreased expression of its target genes involved in energy metabolism and mitochondrial respiratory chain confirming the proteomics data. In addition, other proteomic studies of the same group suggested the deregulation of mitochondrial proteins and proteins involved in oxidative phosphorylation or glycolysis/gluconeogenesis either in cells ( 2.5 Gy gamma-irradiation of EA.hy926 cells, evaluation after 4 and $24 \mathrm{~h}$ ) or mouse hearts (total body irradiation with $3 \mathrm{~Gy}$ gamma-ray and sacrificed after 5-24 h) (97). Furthermore, posttranslational acetylation alterations in primary human cardiac microvascular endothelial cells $4 \mathrm{~h}$ after a gamma radiation dose of 2 Gy indicated radiation-induced changes in, amongst others, mitochondrial proteins (154). Finally, an impaired energy metabolism and perturbation of the insulin/insulin-like growth factor (IGF)-PI3K-Akt signalling pathway was identified by validated proteomic data in cardiac microvascular endothelial cells from wild-type mice that received a local X-ray dose of 8 or $16 \mathrm{~Gy}$ and that were sacrificed after 16 weeks (98).

iii) Radiation-induced premature senescence. Ionizing radiation is a well-known stressor that induces premature senescence in cells (158). The culprit is most likely severe irreparable radiation-induced DSB (155), although radiation-induced accelerated telomere attrition has also been suggested (156). In addition, oxidative stress is a major player in radiation-induced senescence and is involved in both radiation-induced DNA damage and accelerated telomere attrition (156-158).

In several in vitro studies, it has been demonstrated that ionizing radiation induces endothelial cell senescence, mainly with exposure to higher doses of radiation (159-162). Most studies confirm that radiation-induced premature endothelial senescence is implemented by the engagement of the classical DNA damage response pathways, similar to replicative senescence $(159,160,163)$. For instance, Kim et al observed that exposure to $4 \mathrm{~Gy}$ led to a senescent phenotype in endothelial cells. An increased formation of $\gamma-\mathrm{H} 2 \mathrm{AX}$ foci and he consequent activation of the DNA damage response was observed, as indicated by the upregulation of p53 and p 21 and the downregulation of cyclins and $\mathrm{Rb}$ phosphorylation (162).

Interesting studies were carried out to examine the effect of chronic low-dose rate irradiation $(1.4,2.4$ and $4.1 \mathrm{mGy} / \mathrm{h})(164,165)$. Endothelial cells were exposed for 1,3 and 6 weeks, to determine whether chronic low-dose rate radiation changes the onset of replicative senescence, as measured by SA- $\beta$-gal activity and the proliferation rate. Their findings are indicative of a threshold dose rate for the induction of premature senescence. Exposure to $1.4 \mathrm{mGy} / \mathrm{h}$ did not accelerate the onset of senescence, whereas exposure to 2.4 and $4.1 \mathrm{mGy} / \mathrm{h}$ did. Remarkably, a senescent profile was observed when the accumulated doses received by the cells reached 4 Gy. Proteomic analysis revealed a role for radiation-induced oxidative stress and DNA damage, resulting in the induction of the p53/p21 pathway (164). A role of the PI3K/Akt/mTOR pathway was also suggested (165).

In a related transcriptomic study, the gene expression profile was studied in HUVECs that were exposed to chronic low-dose rate ionizing radiation $(1.4$ and $4.1 \mathrm{mGy} / \mathrm{h})$ for either 1,3 or 6 weeks. Using a dual approach, combining single gene expression analysis and Gene Set Enrichment Analysis, an early stress response with p53 signalling, cell cycle changes, DNA repair and apoptosis were observed after 1 week of exposure to both dose rates. This early response disappeared after 3 and 6 weeks 
of chronic low-dose rate radiation exposure $(4.1 \mathrm{mGy} / \mathrm{h})$, and was replaced by the development of an inflammation-related profile. After a period of 6 weeks, the early stress response along with the associated inflammation led to the induction of premature senescence in the $4.1 \mathrm{mGy} / \mathrm{h}$-exposed samples. This premature senescence was stress-related and showed a possible role of IGF binding protein 5 signalling, known to be involved in the regulation of cellular senescence (166).

Validated proteomic data concerning cardiac microvascular endothelial cells that were isolated form wild-type mice that received local X-ray heart doses of 8 or $16 \mathrm{~Gy}$ and that were sacrificed after 16 weeks also strongly suggested enhanced inflammation as the main causes of radiation-induced longterm vascular dysfunction (98).

\section{Conclusion}

We are all exposed to ionizing radiation, from naturally occurring substances with unstable nuclei to X-rays for medical diagnostics. A pressing question is whether or not exposure to these very low doses can cause damage to our health. From epidemiological studies, it is suggested that CVD may be a health risk associated with radiation exposure. However, with exposure to doses $<0.5 \mathrm{~Gy}$, an increased risk cannot be evidenced by epidemiology alone, and a better understanding of the underlying biological and molecular mechanisms is needed. In this way, the current radiation protection system can be refined, making it possible to more accurately assess the cardiovascular risk in the low-dose region. The only way to unequivocally demonstrate the cardiovascular effects of low-dose ionizing radiation is to use dedicated or specialized in vitro and in vivo systems representing the cardiovascular system. In these systems, the endothelium is believed to be a critical target of ionizing radiation exposure due to its crucial role in maintaining the vascular homeostasis in the human body. Over the years, many underlying causes of endothelial dysfunction following exposure to ionizing radiation have been studied, such as nitric oxide bioavailability, premature cell senescence and dysfunction of the mitochondria. However, results in these fields are ambiguous and more research is required to resolve their inconsistencies. These efforts are not in vain, since not only can these findings be used to ameliorate the current radiation protection system, but they can also be used to devise cardiovascular risk-reducing strategies, which can limit the number of patients suffering from CVD worldwide.

\section{Acknowledgements}

This review is written in the context of a study that was funded by the EU FP7 DoReMi (grant agreement 249689) on 'low dose research towards multidisciplinary integration', by the EU FP7 Procardio project (grant agreement 295823), and by the Federal Agency of Nuclear Control (FANC-AFCN, Belgium) (grant agreement CO-90-13-3289-00). In addition, we would like to thank Dr Markus Eidemüller, Dr Cristoforo Simonetto and Professor Helmut Schöllnberger (all from Helmholtz Zentrum München) for their useful comments. C. Rombouts was supported by a doctoral SCK•CEN/Ghent University grant. B. Baselet is supported by a doctoral SCK·CEN/Université catholique de Louvain grant.

\section{References}

1. Stewart JR and Fajardo LF: Radiation-induced heart disease. Clinical and experimental aspects. Radiol Clin North Am 9: 511-531, 1971.

2. Stewart FA: Mechanisms and dose-response relationships for radiation-induced cardiovascular disease. Ann ICRP 41: 72-79, 2012.

3. Schultz-Hector S and Trott KR: Radiation-induced cardiovascular diseases: Is the epidemiologic evidence compatible with the radiobiologic data? Int J Radiat Oncol Biol Phys 67: 10-18, 2007.

4. Clarke M, Collins R, Darby S, Davies C, Elphinstone P, Evans V, Godwin J, Gray R, Hicks C, James S, et al; Early Breast Cancer Trialists' Collaborative Group (EBCTCG): Effects of radiotherapy and of differences in the extent of surgery for early breast cancer on local recurrence and 15-year survival: An overview of the randomised trials. Lancet 366: 2087-2106, 2005.

5. Darby SC, Cutter DJ, Boerma M, Constine LS, Fajardo LF, Kodama K, Mabuchi K, Marks LB, Mettler FA, Pierce LJ, et al: Radiation-related heart disease: Current knowledge and future prospects. Int J Radiat Oncol Biol Phys 76: 656-665, 2010.

6. Darby SC, McGale P, Taylor CW and Peto R: Long-term mortality from heart disease and lung cancer after radiotherapy for early breast cancer: Prospective cohort study of about 300,000 women in US SEER cancer registries. Lancet Oncol 6: 557-565, 2005.

7. McGale P, Darby SC, Hall P, Adolfsson J, Bengtsson NO, Bennet AM, Fornander T, Gigante B, Jensen MB, Peto R, et al: Incidence of heart disease in 35,000 women treated with radiotherapy for breast cancer in Denmark and Sweden. Radiother Oncol 100: 167-175, 2011.

8. Carr ZA, Land CE, Kleinerman RA, Weinstock RW, Stovall M, Griem ML and Mabuchi K: Coronary heart disease after radiotherapy for peptic ulcer disease. Int J Radiat Oncol Biol Phys 61: 842-850, 2005 .

9. Advisory Group on Ionising Radiation A: Circulatory disease risk. Report of the independent Advisory Group on Ionising Radiation. Health Protection Agency, London, 2010.

10. Yusuf SW, Sami S and Daher IN: Radiation-induced heart disease: A clinical update. Cardiol Res Pract 2011: 317659, 2011.

11. Schweizer E: Über spezifische Röntgenschädigungen des Herzmuskels. Strahlentherapie 18: 812-828, 1924 (In German).

12. Aleman BM, van den Belt-Dusebout AW, Klokman WJ, Van't Veer MB, Bartelink H and van Leeuwen FE: Long-term cause-specific mortality of patients treated for Hodgkin's disease. J Clin Oncol 21: 3431-3439, 2003.

13. Hoppe RT: Hodgkin's disease: Complications of therapy and excess mortality. Ann Oncol 8 (Suppl 1): 115-118, 1997.

14. Ng AK, Bernardo MP, Weller E, Backstrand KH, Silver B, Marcus KC, Tarbell NJ, Friedberg J, Canellos GP and Mauch PM: Long-term survival and competing causes of death in patients with early-stage Hodgkin's disease treated at age 50 or younger. J Clin Oncol 20: 2101-2108, 2002.

15. Swerdlow AJ,Higgins CD, Smith P, Cunningham D, Hancock BW, Horwich A, Hoskin PJ, Lister A, Radford JA, Rohatiner AZ and Linch DC: Myocardial infarction mortality risk after treatment for Hodgkin disease: A collaborative British cohort study. J Natl Cancer Inst 99: 206-214, 2007.

16. Darby SC, Ewertz M, McGale P, Bennet AM, Blom-Goldman U, Brønnum D, Correa C, Cutter D, Gagliardi G, Gigante B, et al: Risk of ischemic heart disease in women after radiotherapy for breast cancer. N Engl J Med 368: 987-998, 2013.

17. Ozasa K, Shimizu Y, Sakata R, Sugiyama H, Grant EJ, Soda M, Kasagi F and Suyama A: Risk of cancer and non-cancer diseases in the atomic bomb survivors. Radiat Prot Dosimetry 146: 272-275, 2011.

18. Takahashi I, Abbott RD, Ohshita T, Takahashi T, Ozasa K, Akahoshi M, Fujiwara S, Kodama K and Matsumoto M: A prospective follow-up study of the association of radiation exposure with fatal and non-fatal stroke among atomic bomb survivors in Hiroshima and Nagasaki (1980-2003). BMJ Open 2: e000654, 2012.

19. Preston DL, Shimizu Y, Pierce DA, Suyama A and Mabuchi K: Studies of mortality of atomic bomb survivors. Report 13: Solid cancer and noncancer disease mortality: 1950-1997. Radiat Res 160: 381-407, 2003.

20. Shimizu Y, Pierce DA, Preston DL and Mabuchi K: Studies of the mortality of atomic bomb survivors. Report 12, part II. Noncancer mortality: 1950-1990. Radiat Res 152: 374-389, 1999. 
21. Shimizu Y, Kodama K, Nishi N, Kasagi F, Suyama A, Soda M, Grant EJ, Sugiyama H, Sakata R, Moriwaki H, et al: Radiation exposure and circulatory disease risk: Hiroshima and Nagasaki atomic bomb survivor data, 1950-2003. BMJ 340: b5349, 2010.

22. Little MP, Azizova TV, Bazyka D, Bouffler SD, Cardis E, Chekin S, Chumak VV, Cucinotta FA, de Vathaire F, Hall P, et al: Comment on 'dose-responses from multi-model inference for the non-cancer disease mortality of atomic bomb survivors' (Radiat. Environ. Biophys (2012) 51:165-178) by Schöllnberger et al. Radiat Environ Biophys 52: 157-159, 2013.

23. Schöllnberger H, Ozasa K, Neff F and Kaiser JC: Cardiovascular disease mortality of A-bomb survivors and the healthy survivor selection effect. Radiat Prot Dosimetry 166: 320-323, 2015.

24. Vrijheid M, Cardis E, Ashmore P, Auvinen A, Bae JM, Engels H, Gilbert E, Gulis G, Habib R, Howe G, et al: Mortality from diseases other than cancer following low doses of ionizing radiation: Results from the 15-Country Study of nuclear industry workers. Int J Epidemiol 36: 1126-1135, 2007.

25. Ivanov VK, Maksioutov MA, Chekin SY, Petrov AV, Biryukov AP, Kruglova ZG, Matyash VA, Tsyb AF, Manton KG and Kravchenko JS: The risk of radiation-induced cerebrovascular disease in Chernobyl emergency workers. Health Phys 90: 199-207, 2006.

26. Muirhead CR, O'Hagan JA, Haylock RG, Phillipson MA, Willcock T, Berridge GL and Zhang W: Mortality and cancer incidence following occupational radiation exposure: Third analysis of the National Registry for Radiation Workers. Br J Cancer 100: 206-212, 2009.

27. Ashmore JP, Krewski D, Zielinski JM, Jiang H, Semenciw R and Band PR: First analysis of mortality and occupational radiation exposure based on the National Dose Registry of Canada. Am J Epidemiol 148: 564-574, 1998.

28. Rajaraman P, Doody MM, Yu CL, Preston DL, Miller JS, Sigurdson AJ, Freedman DM, Alexander BH, Little MP, Miller DL and Linet MS: Incidence and mortality risks for circulatory diseases in US radiologic technologists who worked with fluoroscopically guided interventional procedures, 1994-2008. Occup Environ Med 73: 21-27, 2016.

29. Azizova TV, Day RD, Wald N, Muirhead CR, O'Hagan JA, Sumina MV, Belyaeva ZD, Druzhinina MB, Teplyakov II, Semenikhina NG, et al: The 'clinic' medical-dosimetric database of Mayak production association workers: Structure, characteristics and prospects of utilization. Health Phys 94: 449-458, 2008

30. Azizova TV, Muirhead CR, Druzhinina MB, Grigoryeva ES, Vlasenko EV, Sumina MV, O'Hagan JA, Zhang W, Haylock RG and Hunter N: Cardiovascular diseases in the cohort of workers first employed at Mayak PA in 1948-1958. Radiat Res 174 155-168, 2010.

31. Azizova TV, Muirhead CR, Moseeva MB, Grigoryeva ES, Vlasenko EV, Hunter N, Haylock RG and O'Hagan JA: Ischemic heart disease in nuclear workers first employed at the Mayak PA in 1948-1972. Health Phys 103: 3-14, 2012.

32. Simonetto C, Azizova TV, Grigoryeva ES, Kaiser JC, Schöllnberger $\mathrm{H}$ and Eidemüller $\mathrm{M}$ : Ischemic heart disease in workers at Mayak PA: Latency of incidence risk after radiation exposure. PLoS One 9: e96309, 2014.

33. Azizova TV, Grigoryeva ES, Haylock RG, Pikulina MV and Moseeva MB: Ischaemic heart disease incidence and mortality in an extended cohort of Mayak workers first employed in 1948-1982. Br J Radiol 88: 20150169, 2015.

34. Azizova TV, Haylock RG, Moseeva MB, Bannikova MV and Grigoryeva ES: Cerebrovascular diseases incidence and mortality in an extended Mayak Worker Cohort 1948-1982. Radiat Res 182: 529-544, 2014

35. Simonetto C, Schöllnberger H, Azizova TV, Grigoryeva ES, Pikulina MV and Eidemüller M: Cerebrovascular Diseases in Workers at Mayak PA: The Difference in Radiation Risk between Incidence and Mortality. PLoS One 10: e0125904, 2015.

36. Little MP, Azizova TV,Bazyka D, Bouffler SD, Cardis E, Chekin S, Chumak VV, Cucinotta FA, de Vathaire F, Hall P, et al: Systematic review and meta-analysis of circulatory disease from exposure to low-level ionizing radiation and estimates of potential population mortality risks. Environ Health Perspect 120: 1503-1511, 2012.

37. Schöllnberger H, Kaiser JC, Jacob P and Walsh L: Dose-responses from multi-model inference for the non-cancer disease mortality of atomic bomb survivors. Radiat Environ Biophys 51: 165-178, 2012.
38. Working Party on Research Implications on Health and Safety SotAGoE: Emerging evidence for radiation induced circulatory diseases. Radiation Protection No 158. EU Scientific Seminar 2008, Luxembourg, November 25, 2008.

39. United Nations Scientific Committee on the Effects of Atomic Radiation: Annex B: Epidemiological evaluation of cardiovascular disease and other non-cancer diseases following radiation exposure. UNSCEAR 2006 Report Vol. 1. United Nations, New York, 2006.

40. Montgomery JE and Brown JR: Metabolic biomarkers for predicting cardiovascular disease. Vasc Health Risk Manag 9: 37-45, 2013

41. Brenner DJ, Doll R, Goodhead DT, Hall EJ, Land CE, Little JB, Lubin JH, Preston DL, Preston RJ, Puskin JS, et al: Cancer risks attributable to low doses of ionizing radiation: Assessing what we really know. Proc Natl Acad Sci USA 100: 13761-13766, 2003.

42. Borghini A, Gianicolo EA, Picano E and Andreassi MG: Ionizing radiation and atherosclerosis: Current knowledge and future challenges. Atherosclerosis 230: 40-47, 2013.

43. Seddon B, Cook A, Gothard L, Salmon E, Latus K, Underwood SR and Yarnold J: Detection of defects in myocardial perfusion imaging in patients with early breast cancer treated with radiotherapy. Radiother Oncol 64: 53-63, 2002.

44. Chung E, Corbett JR, Moran JM, Griffith KA, Marsh RB, Feng M, Jagsi R, Kessler ML, Ficaro EC and Pierce LJ: Is there a dose-response relationship for heart disease with low-dose radiation therapy? Int J Radiat Oncol Biol Phys 85: 959-964, 2013.

45. Januzzi JL Jr: Natriuretic peptide testing: A window into the diagnosis and prognosis of heart failure. Cleve Clin J Med 73 149-152, 155-147, 2006.

46. Palazzuoli A, Gallotta M, Quatrini I and Nuti R: Natriuretic peptides (BNP and NT-proBNP): Measurement and relevance in heart failure. Vasc Health Risk Manag 6: 411-418, 2010.

47. Sabatine MS, Morrow DA, de Lemos JA, Omland T, Sloan S, Jarolim P, Solomon SD, Pfeffer MA and Braunwald E: Evaluation of multiple biomarkers of cardiovascular stress for risk prediction and guiding medical therapy in patients with stable coronary disease. Circulation 125: 233-240, 2012

48. D'Errico MP, Grimaldi L, Petruzzelli MF, Gianicolo EA, Tramacere F, Monetti A, Placella R, Pili G, Andreassi MG, Sicari R, et al: N-terminal pro-B-type natriuretic peptide plasma levels as a potential biomarker for cardiac damage after radiotherapy in patients with left-sided breast cancer. Int J Radiat Oncol Biol Phys 82: e239-e246, 2012.

49. Preston RJ1, Boice JD Jr, Brill AB, Chakraborty R, Conolly R, Hoffman FO, Hornung RW, Kocher DC, Land CE, Shore RE and Woloschak GE: Uncertainties in estimating health risks associated with exposure to ionising radiation. J Radiol Prot 33: 573-588, 2013.

50. Authors on behalf of ICRP, Stewart FA, Akleyev AV, HauerJensen M, Hendry JH, Kleiman NJ, Macvittie TJ, Aleman BM, Edgar AB, Mabuchi K, Muirhead CR, et al: ICRP publication 118: ICRP statement on tissue reactions and early and late effects of radiation in normal tissues and organ - threshold doses for tissue reactions in a radiation protection context. Ann ICRP 41: 1-322, 2012.

51. United Nations Scientific Committee on the Effects of Atomic Radiation: Annex A: Medical Radiation Exposures. UNSCEAR 2008 Report Vol. 1. United Nations, New York, 2006.

52. Hall EJ and Brenner DJ: Cancer risks from diagnostic radiology. Br J Radiol 81: 362-378, 2008.

53. Einstein AJ and Knuuti J: Cardiac imaging: Does radiation matter? Eur Heart J 33: 573-578, 2012.

54. Shapiro BP, Mergo PJ, Snipelisky DF, Kantor B and Gerber TC: Radiation dose in cardiac imaging: How should it affect clinical decisions? AJR Am J Roentgenol 200: 508-514, 2013.

55. Miller JA, Raichlin E, Williamson EE, McCully RB, Pellikka PA, Hodge DO, Miller TD, Gibbons RJ and Araoz PA: Evaluation of coronary CTA Appropriateness Criteria in an academic medical center. J Am Coll Radiol 7: 125-131, 2010

56. Hendel RC, Cerqueira M, Douglas PS, Caruth KC, Allen JM, Jensen NC, Pan W, Brindis R and Wolk M: A multicenter assessment of the use of single-photon emission computed tomography myocardial perfusion imaging with appropriateness criteria. J Am Coll Cardiol 55: 156-162, 2010.

57. Picano E and Vano E: The radiation issue in cardiology: The time for action is now. Cardiovasc Ultrasound 9: 35, 2011.

58. Paterick TE, Jan MF, Paterick ZR, Tajik AJ and Gerber TC: Cardiac imaging modalities with ionizing radiation: The role of informed consent. JACC Cardiovasc Imaging 5: 634-640, 2012. 
59. Halliburton SS and Schoenhagen P: Cardiovascular imaging with computed tomography: Responsible steps to balancing diagnostic yield and radiation exposure. JACC Cardiovasc Imaging 3: 536-540, 2010.

60. Pernot E, Hall J, Baatout S, Benotmane MA, Blanchardon E, Bouffler S, El Saghire H, Gomolka M, Guertler A, HarmsRingdahl M, et al: Ionizing radiation biomarkers for potential use in epidemiological studies. Mutat Res 751: 258-286, 2012.

61. Adams MJ, Hardenbergh PH, Constine LS and Lipshultz SE: Radiation-associated cardiovascular disease. Crit Rev Oncol Hematol 45: 55-75, 2003

62. Adams MJ, Lipshultz SE, Schwartz C, Fajardo LF, Coen V and Constine LS: Radiation-associated cardiovascular disease: Manifestations and management. Semin Radiat Oncol 13: 346-356, 2003.

63. Zaragoza C, Gomez-Guerrero C, Martin-Ventura JL, Blanco-Colio L, Lavin B, Mallavia B, Tarin C, Mas S, Ortiz A and Egido J: Animal models of cardiovascular diseases. J Biomed Biotechnol 2011: 497841, 2011.

64. Zadelaar S, Kleemann R, Verschuren L, de Vries-Van der Weij J, van der Hoorn J, Princen HM and Kooistra T: Mouse models for atherosclerosis and pharmaceutical modifiers. Arterioscler Thromb Vasc Biol 27: 1706-1721, 2007.

65. Ohashi R, Mu H, Yao Q and Chen C: Cellular and molecular mechanisms of atherosclerosis with mouse models. Trends Cardiovasc Med 14: 187-190, 2004.

66. Yamashita A and Asada Y: A rabbit model of thrombosis on atherosclerotic lesions. J Biomed Biotechnol 2011: 424929, 2011.

67. Scherer E, Streffer C and Trott KR (eds). Radiopathology of Organs and Tissues. Springer Verlag, Berlin, 1991.

68. Fajardo LF and Stewart JR: Experimental radiation-induced heart disease. I. Light microscopic studies. Am J Pathol 59: 299-316, 1970

69. Gavin PR and Gillette EL: Radiation response of the canine cardiovascular system. Radiat Res 90: 489-500, 1982.

70. Lauk S, Kiszel Z, Buschmann J and Trott KR: Radiation-induced heart disease in rats. Int J Radiat Oncol Biol Phys 11: 801-808, 1985.

71. Lusis AJ: Atherosclerosis. Nature 407: 233-241, 2000.

72. Virmani R, Kolodgie FD, Burke AP, Finn AV, Gold HK, Tulenko TN, Wrenn SP and Narula J: Atherosclerotic plaque progression and vulnerability to rupture: Angiogenesis as a source of intraplaque hemorrhage. Arterioscler Thromb Vasc Biol 25: 2054-2061, 2005.

73. Mitchel RE, Hasu M, Bugden M, Wyatt H, Hildebrandt G, Chen YX, Priest ND and Whitman SC: Low-dose radiation exposure and protection against atherosclerosis in $\mathrm{ApoE}(-/-)$ mice: The influence of P53 heterozygosity. Radiat Res 179: 190-199, 2013.

74. Stewart FA, Heeneman S, Te Poele J, Kruse J, Russell NS Gijbels $\mathrm{M}$ and Daemen $\mathrm{M}$ : Ionizing radiation accelerates the development of atherosclerotic lesions in $\mathrm{ApoE}^{-/-}$mice and predisposes to an inflammatory plaque phenotype prone to hemorrhage. Am J Pathol 168: 649-658, 2006.

75. Gabriels K, Hoving S, Seemann I, Visser NL, Gijbels MJ, Pol JF, Daemen MJ, Stewart FA and Heeneman S: Local heart irradiation of ApoE(-/-) mice induces microvascular and endocardial damage and accelerates coronary atherosclerosis. Radiother Oncol 105: 358-364, 2012.

76. Hoving S, Heeneman S, Gijbels MJ, te Poele JA, Russell NS, Daemen MJ and Stewart FA: Single-dose and fractionated irradiation promote initiation and progression of atherosclerosis and induce an inflammatory plaque phenotype in ApoE(-/-) mice. Int J Radiat Oncol Biol Phys 71: 848-857, 2008.

77. Mitchel RE, Hasu M, Bugden M, Wyatt H, Little MP, Gola A Hildebrandt G, Priest ND and Whitman SC: Low-dose radiation exposure and atherosclerosis in $\mathrm{ApoE}^{-/-}$mice. Radiat Res 175: 665-676, 2011.

78. Mancuso M,Pasquali E, Braga-Tanaka I III, Tanaka S, Pannicelli A, Giardullo P, Pazzaglia S, Tapio S, Atkinson MJ and Saran A: Acceleration of atherogenesis in $\mathrm{ApoE}^{-/}$mice exposed to acute or low-dose-rate ionizing radiation. Oncotarget 6: 31263-31271, 2015

79. Le Gallic C, Phalente Y, Manens L, Dublineau I, Benderitter M, Gueguen Y, Lehoux S and Ebrahimian TG: Chronic internal exposure to low dose ${ }^{137} \mathrm{Cs}$ induces positive impact on the stability of atherosclerotic plaques by reducing inflammation in $\mathrm{ApoE}^{-/-}$mice. PLoS One 10: e0128539, 2015

80. Jeon YH, Kraus SG, Jowsey T and Glasgow NJ: The experience of living with chronic heart failure: A narrative review of qualitative studies. BMC Health Serv Res 10: 77, 2010.

81. Lauk S: Endothelial alkaline phosphatase activity loss as an early stage in the development of radiation-induced heart disease in rats. Radiat Res 110: 118-128, 1987.
82. Schultz-Hector S: Radiation-induced heart disease: Review of experimental data on dose response and pathogenesis. Int J Radiat Biol 61: 149-160, 1992.

83. Franken NA, Camps JA, van Ravels FJ, van der Laarse A, Pauwels EK and Wondergem J: Comparison of in vivo cardiac function with ex vivo cardiac performance of the rat heart after thoracic irradiation. Br J Radiol 70: 1004-1009, 1997.

84. Seemann I, Gabriels K, Visser NL, Hoving S, te Poele JA, Pol JF, Gijbels MJ, Janssen BJ, van Leeuwen FW, Daemen MJ, et al: Irradiation induced modest changes in murine cardiac function despite progressive structural damage to the myocardium and microvasculature. Radiother Oncol 103: 143-150, 2012.

85. Monceau V, Meziani L, Strup-Perrot C, Morel E, Schmidt M, Haagen J, Escoubet B, Dörr W and Vozenin MC: Enhanced sensitivity to low dose irradiation of $\mathrm{ApoE}^{-/-}$mice mediated by early pro-inflammatory profile and delayed activation of the TGF $\beta 1$ cascade involved in fibrogenesis. PLoS One 8: e57052, 2013.

86. Hendry JH, Akahoshi M, Wang LS, Lipshultz SE, Stewart FA and Trott KR: Radiation-induced cardiovascular injury. Radiat Environ Biophys 47: 189-193, 2008.

87. Little MP, Tawn EJ, Tzoulaki I, Wakeford R, Hildebrandt G, Paris F, Tapio $S$ and Elliott P: A systematic review of epidemiological associations between low and moderate doses of ionizing radiation and late cardiovascular effects, and their possible mechanisms. Radiat Res 169: 99-109, 2008.

88. Bhatti P, Sigurdson AJ and Mabuchi K: Can low-dose radiation increase risk of cardiovascular disease? Lancet 372: 697-699, 2008.

89. Hildebrandt G: Non-cancer diseases and non-targeted effects. Mutat Res 687: 73-77, 2010.

90. Hildebrandt G, Maggiorella L, Rödel F, Rödel V, Willis D and Trott KR: Mononuclear cell adhesion and cell adhesion molecule liberation after X-irradiation of activated endothelial cells in vitro. Int J Radiat Biol 78: 315-325, 2002.

91. Sievert W, Trott KR, Azimzadeh O, Tapio S, Zitzelsberger H and Multhoff G: Late proliferating and inflammatory effects on murine microvascular heart and lung endothelial cells after irradiation. Radiother Oncol 117: 376-381, 2015.

92. Hallahan DE, Virudachalam S and Kuchibhotla J: Nuclear factor kappaB dominant negative genetic constructs inhibit X-ray induction of cell adhesion molecules in the vascular endothelium. Cancer Res 58: 5484-5488, 1998.

93. Van Der Meeren A, Squiban C, Gourmelon P, Lafont H and Gaugler MH: Differential regulation by IL-4 and IL-10 of radiationinduced IL- 6 and IL- 8 production and ICAM-1 expression by human endothelial cells. Cytokine 11: 831-838, 1999.

94. Milliat F, François A, Isoir M, Deutsch E, Tamarat R, Tarlet G, Atfi A, Validire P, Bourhis J, Sabourin JC and Benderitter M: Influence of endothelial cells on vascular smooth muscle cells phenotype after irradiation: Implication in radiation-induced vascular damages. Am J Pathol 169: 1484-1495, 2006.

95. Hayashi T, Morishita Y, Khattree R, Misumi M, Sasaki K, Hayashi I, Yoshida K, Kajimura J, Kyoizumi S, Imai K, et al: Evaluation of systemic markers of inflammation in atomicbomb survivors with special reference to radiation and age effects. FASEB J 26: 4765-4773, 2012.

96. Wang J, Zheng H, Ou X, Fink LM and Hauer-Jensen M: Deficiency of microvascular thrombomodulin and upregulation of protease-activated receptor-1 in irradiated rat intestine: Possible link between endothelial dysfunction and chronic radiation fibrosis. Am J Pathol 160: 2063-2072, 2002.

97. Azimzadeh O, Scherthan H, Sarioglu H, Barjaktarovic Z, Conrad M, Vogt A, Calzada-Wack J, Neff F, Aubele M, BuskeC, et al: Rapid proteomic remodeling of cardiac tissue caused by total body ionizing radiation. Proteomics 11: 3299-3311, 2011.

98. Azimzadeh O, Sievert W, Sarioglu H, Merl-Pham J, Yentrapalli R, Bakshi MV, Janik D, Ueffing M, Atkinson MJ, Multhoff G and Tapio S: Integrative proteomics and targeted transcriptomics analyses in cardiac endothelial cells unravel mechanisms of long-term radiation-induced vascular dysfunction. J Proteome Res 14: 1203-1219, 2015.

99. Trott KR and Kamprad F: Radiobiological mechanisms of antiinflammatory radiotherapy. Radiother Oncol 51: 197-203, 1999.

100. Seegenschmiedt MH, Katalinic A, Makoski HB, Haase W, Gademann $G$ and Hassenstein E: Radiotherapy of benign diseases: A pattern of care study in Germany. Strahlenther Onkol 175: 541-547, 1999 (In German).

101. Rödel F, Keilholz L, Herrmann M, Sauer R and Hildebrandt G: Radiobiological mechanisms in inflammatory diseases of low-dose radiation therapy. Int J Radiat Biol 83: 357-366, 2007. 
102.Kern PM, Keilholz L, Forster C, Hallmann R, Herrmann M and Seegenschmiedt MH: Low-dose radiotherapy selectively reduces adhesion of peripheral blood mononuclear cells to endothelium in vitro. Radiother Oncol 54: 273-282, 2000.

103. Hirase T and Node K: Endothelial dysfunction as a cellular mechanism for vascular failure. Am J Physiol Heart Circ Physiol 302: H499-H505, 2012.

104. Flammer AJ and Lüscher TF: Three decades of endothelium research: From the detection of nitric oxide to the everyday implementation of endothelial function measurements in cardiovascular diseases. Swiss Med Wkly 140: w13122, 2010.

105. Triggle CR, Samuel SM, Ravishankar S, Marei I, Arunachalam G and Ding H: The endothelium: Influencing vascular smooth muscle in many ways. Can J Physiol Pharmacol 90: 713-738, 2012.

106. van Hinsbergh VW: Endothelium - role in regulation of coagulation and inflammation. Semin Immunopathol 34: 93-106, 2012.

107. Michiels C: Endothelial cell functions. J Cell Physiol 196: 430-443, 2003.

108. Sandoo A, van Zanten JJ, Metsios GS, Carroll D and Kitas GD: The endothelium and its role in regulating vascular tone. Open Cardiovasc Med J 4: 302-312, 2010.

109. Aird WC: Phenotypic heterogeneity of the endothelium: I. Structure, function, and mechanisms. Circ Res 100: 158-173, 2007.

110. Aird WC: Phenotypic heterogeneity of the endothelium: II. Representative vascular beds. Circ Res 100: 174-190, 2007.

111. Landmesser U, Hornig B and Drexler H: Endothelial function: A critical determinant in atherosclerosis? Circulation 109 (Suppl 1): II27-II33, 2004.

112. Mudau M, Genis A, Lochner A and Strijdom H: Endothelial dysfunction: The early predictor of atherosclerosis. Cardiovasc J Afr 23: 222-231, 2012.

113. Shah AM and Channon KM: Free radicals and redox signalling in cardiovascular disease. Heart 90: 486-487, 2004.

114. Lum H and Roebuck KA: Oxidant stress and endothelial cell dysfunction. Am J Physiol Cell Physiol 280: C719-C741, 2001.

115. Jaffe EA, Nachman RL, Becker CG and Minick CR: Culture of human endothelial cells derived from umbilical veins. Identification by morphologic and immunologic criteria. J Clin Invest 52: 2745-2756, 1973.

116. Gimbrone MA Jr, Cotran RS and Folkman J: Human vascular endothelial cells in culture. Growth and DNA synthesis. J Cell Biol 60: 673-684, 1974.

117. Bicknell R (ed): Endothelial cell culture. Cambridge University Press, 1996.

118. Edgell CJ, McDonald CC and Graham JB: Permanent cell line expressing human factor VIII-related antigen established by hybridization. Proc Natl Acad Sci USA 80: 3734-3737, 1983.

119. Rombouts C, Aerts A, Beck M, De Vos WH, Van Oostveldt P, Benotmane MA and Baatout S: Differential response to acute low dose radiation in primary and immortalized endothelial cells. Int J Radiat Biol 89: 841-850, 2013

120. Dickson MA, Hahn WC, Ino Y, Ronfard V, Wu JY, Weinberg RA, Louis DN, Li FP and Rheinwald JG: Human keratinocytes that express hTERT and also bypass a p16(INK4a)-enforced mechanism that limits life span become immortal yet retain normal growth and differentiation characteristics. Mol Cell Biol 20: 1436-1447, 2000.

121.Bouïs D, Hospers GA, Meijer C, Molema G and Mulder NH: Endothelium in vitro: A review of human vascular endothelial cell lines for blood vessel-related research. Angiogenesis 4 91-102, 2001.

122. Wallace CS and Truskey GA: Direct-contact co-culture between smooth muscle and endothelial cells inhibits TNF-alphamediated endothelial cell activation. Am J Physiol Heart Circ Physiol 299: H338-H346, 2010.

123. Rainger GE and Nash GB: Cellular pathology of atherosclerosis: Smooth muscle cells prime cocultured endothelial cells for enhanced leukocyte adhesion. Circ Res 88: 615-622, 2001.

124. Dietrich F and Lelkes PI: Fine-tuning of a three-dimensional microcarrier-based angiogenesis assay for the analysis of endothelial-mesenchymal cell co-cultures in fibrin and collagen gels. Angiogenesis 9: 111-125, 2006.

125. Vernon RB and Sage EH: A novel, quantitative model for study of endothelial cell migration and sprout formation within threedimensional collagen matrices. Microvasc Res 57: 118-133, 1999.

126. Acheva A, Aerts A, Rombouts C, Baatout S, Salomaa S, Manda K, Hildebrandt G and Kämäräinen M: Human 3-D tissue models in radiation biology: Current status and future perspectives. Int J Radiat Res 12: 81-98, 2014.
127. Goel S, Duda DG, Xu L, Munn LL, Boucher Y, Fukumura D and Jain RK: Normalization of the vasculature for treatment of cancer and other diseases. Physiol Rev 91: 1071-1121, 2011.

128. Zhang HP, Takayama K, Su B, Jiao XD, Li R and Wang JJ: Effect of sunitinib combined with ionizing radiation on endothelial cells. J Radiat Res (Tokyo) 52: 1-8, 2011.

129. Dudley AC: Tumor endothelial cells. Cold Spring Harb Perspect Med 2: a006536, 2012.

130. Jeggo P and Löbrich M: Radiation-induced DNA damage responses. Radiat Prot Dosimetry 122: 124-127, 2006.

131. Bolus NE: Basic review of radiation biology and terminology. J Nucl Med Technol 29: 67-77, 2001.

132. Norbury CJ and Hickson ID: Cellular responses to DNA damage. Annu Rev Pharmacol Toxicol 41: 367-401, 2001.

133. Clarke PR and Allan LA: Cell-cycle control in the face of damage - a matter of life or death. Trends Cell Biol 19: 89-98, 2009.

134.Dikomey E, Dahm-Daphi J, Brammer I, Martensen R and Kaina B: Correlation between cellular radiosensitivity and nonrepaired double-strand breaks studied in nine mammalian cell lines. Int J Radiat Biol 73: 269-278, 1998.

135. Kuo LJ and Yang LX: Gamma-H2AX - a novel biomarker for DNA double-strand breaks. In Vivo 22: 305-309, 2008.

136. Stoneman VE and Bennett MR: Role of apoptosis in atherosclerosis and its therapeutic implications. Clin Sci (Lond) 107: 343-354, 2004.

137. Mercer J, Mahmoudi M and Bennett M: DNA damage, p53, apoptosis and vascular disease. Mutat Res 621: 75-86, 2007.

138. Choy JC, Granville DJ, Hunt DW and McManus BM: Endothelial cell apoptosis: Biochemical characteristics and potential implications for atherosclerosis. J Mol Cell Cardiol 33: 1673-1690, 2001.

139. Haimovitz-Friedman A, Kan CC, Ehleiter D, Persaud RS, McLoughlin M, Fuks Z and Kolesnick RN: Ionizing radiation acts on cellular membranes to generate ceramide and initiate apoptosis. J Exp Med 180: 525-535, 1994.

140. Langley RE, Bump EA, Quartuccio SG, Medeiros D and Braunhut SJ: Radiation-induced apoptosis in microvascular endothelial cells. Br J Cancer 75: 666-672, 1997.

141. Rödel F, Frey B, Capalbo G, Gaipl U, Keilholz L, Voll R, Hildebrandt $G$ and Rödel $C$ : Discontinuous induction of X-linked inhibitor of apoptosis in EA.hy.926 endothelial cells is linked to NF- $\mathrm{KB}$ activation and mediates the anti-inflammatory properties of low-dose ionising-radiation. Radiother Oncol 97: 346-351, 2010

142. Pluder F, Barjaktarovic Z, Azimzadeh O, Mörtl S, Krämer A, Steininger S, Sarioglu H, Leszczynski D, Nylund R, Hakanen A, et al: Low-dose irradiation causes rapid alterations to the proteome of the human endothelial cell line EA.hy926. Radiat Environ Biophys 50: 155-166, 2011.

143. Yu E, Mercer J and Bennett M: Mitochondria in vascular disease. Cardiovasc Res 95: 173-182, 2012.

144.Riley PA: Free radicals in biology: Oxidative stress and the effects of ionizing radiation. Int J Radiat Biol 65: 27-33, 1994.

145. Yamamori T, Yasui H, Yamazumi M, Wada Y, Nakamura Y, Nakamura $\mathrm{H}$ and Inanami O: Ionizing radiation induces mitochondrial reactive oxygen species production accompanied by upregulation of mitochondrial electron transport chain function and mitochondrial content under control of the cell cycle checkpoint. Free Radic Biol Med 53: 260-270, 2012.

146. Bernardi P: The mitochondrial permeability transition pore: A mystery solved? Front Physiol 4: 95, 2013.

147. Leach JK, Van Tuyle G, Lin PS, Schmidt-Ullrich R and Mikkelsen RB: Ionizing radiation-induced, mitochondriadependent generation of reactive oxygen/nitrogen. Cancer Res 61: 3894-3901, 2001

148. Prithivirajsingh S, Story MD, Bergh SA, Geara FB, Ang KK, Ismail SM, Stevens CW, Buchholz TA and Brock WA: Accumulation of the common mitochondrial DNA deletion induced by ionizing radiation. FEBS Lett 571: 227-232, 2004.

149. Wang L, Kuwahara Y, Li L, Baba T, Shin RW, Ohkubo Y, Ono K and Fukumoto M: Analysis of Common Deletion (CD) and a novel deletion of mitochondrial DNA induced by ionizing radiation. Int J Radiat Biol 83: 433-442, 2007.

150. Schilling-Tóth B, Sándor N, Kis E, Kadhim M, Sáfrány G and Hegyesi H: Analysis of the common deletions in the mitochondrial DNA is a sensitive biomarker detecting direct and non-targeted cellular effects of low dose ionizing radiation. Mutat Res 716: 33-39, 2011. 
151. Barjaktarovic Z, Schmaltz D, Shyla A, Azimzadeh O, Schulz S, Haagen J, Dörr W, Sarioglu H, Schäfer A, Atkinson MJ, et al: Radiation-induced signaling results in mitochondrial impairment in mouse heart at 4 weeks after exposure to X-rays. PLoS One 6: e27811, 2011

152. Barjaktarovic Z, Shyla A, Azimzadeh O, Schulz S, Haagen J, Dörr W, Sarioglu H, Atkinson MJ, Zischka H and Tapio S: Ionising radiation induces persistent alterations in the cardiac mitochondrial function of C57BL/6 mice 40 weeks after local heart exposure. Radiother Oncol 106: 404-410, 2013.

153. Azimzadeh O, Sievert W, Sarioglu H, Yentrapalli R, Barjaktarovic Z, Sriharshan A, Ueffing M, Janik D, Aichler M, Atkinson MJ, et al: PPAR alpha: A novel radiation target in locally exposed Mus musculus heart revealed by quantitative proteomics. J Proteome Res 12: 2700-2714, 2013.

154.Barjaktarovic Z, Kempf SJ, Sriharshan A, Merl-Pham J, Atkinson MJ and Tapio S: Ionizing radiation induces immediate protein acetylation changes in human cardiac microvascular endothelial cells. J Radiat Res (Tokyo) 56: 623-632, 2015.

155. Vávrová $J$ and Rezáčová $M$ : The importance of senescence in ionizing radiation-induced tumour suppression. Folia Biol (Praha) 57: 41-46, 2011.

156. Sabatino L, Picano E and Andreassi MG: Telomere shortening and ionizing radiation: A possible role in vascular dysfunction? Int J Radiat Biol 88: 830-839, 2012.

157.Kurz DJ, Decary S, Hong Y, Trivier E, Akhmedov A and Erusalimsky JD: Chronic oxidative stress compromises telomere integrity and accelerates the onset of senescence in human endothelial cells. J Cell Sci 117: 2417-2426, 2004.

158. Campisi J and d'Adda di Fagagna F: Cellular senescence: When bad things happen to good cells. Nat Rev Mol Cell Biol 8: 729-740, 2007.

159. Oh CW, Bump EA, Kim JS, Janigro D and Mayberg MR: Induction of a senescence-like phenotype in bovine aortic endothelial cells by ionizing radiation. Radiat Res 156: 232-240, 2001.
160. Panganiban RA, Mungunsukh O and Day RM: X-irradiation induces ER stress, apoptosis, and senescence in pulmonary artery endothelial cells. Int J Radiat Biol 89: 656-667, 2013.

161. Igarashi K, Sakimoto I, Kataoka K, Ohta K and Miura M: Radiation-induced senescence-like phenotype in proliferating and plateau-phase vascular endothelial cells. Exp Cell Res 313 3326-3336, 2007.

162. Kim KS, Kim JE, Choi KJ, Bae S and Kim DH: Characterization of DNA damage-induced cellular senescence by ionizing radiation in endothelial cells. Int J Radiat Biol 90: 71-80, 2014.

163. Suzuki K, Mori I, Nakayama Y, Miyakoda M, Kodama S and Watanabe M: Radiation-induced senescence-like growth arrest requires TP53 function but not telomere shortening. Radiat Res 155: 248-253, 2001.

164. Yentrapalli R, Azimzadeh O, Barjaktarovic Z, Sarioglu H, Wojcik A, Harms-Ringdahl M, Atkinson MJ, Haghdoost S and Tapio S: Quantitative proteomic analysis reveals induction of premature senescence in human umbilical vein endothelial cells exposed to chronic low-dose rate gamma radiation. Proteomics 13: 1096-1107, 2013

165. Yentrapalli R, Azimzadeh O, Sriharshan A, Malinowsky K, Merl J, Wojcik A, Harms-Ringdahl M, Atkinson MJ, Becker KF, Haghdoost S and Tapio S: The PI3K/Akt/mTOR pathway is implicated in the premature senescence of primary human endothelial cells exposed to chronic radiation. PLoS One 8: e70024, 2013.

166. Rombouts C, Aerts A, Quintens R, Baselet B, El-Saghire H, Harms-Ringdahl M, Haghdoost S, Janssen A, Michaux A, Yentrapalli R, et al: Transcriptomic profiling suggests a role for IGFBP5 in premature senescence of endothelial cells after chronic low dose rate irradiation. Int J Radiat Biol 90: 560-574, 2014.

167. Libby P, Ridker PM and Hansson GK: Progress and challenges in translating the biology of atherosclerosis. Nature 473: 317-325, 2011. 